Luiz Felipe Feltrim Julio

Simbolismos associados ao Serviço de Saúde Suplementar por Consumidores de Baixa Renda

Dissertação apresentada ao Programa de Pós-Graduação em Administração de Empresas da PUC-Rio como requisito parcial para obtenção do grau de Mestre em Administração de Empresas.

Orientador: Prof. Marcus Wilcox Hemais 


\section{Simbolismos associados ao Serviço de Saúde Suplementar por Consumidores de Baixa Renda}

Dissertação apresentada como requisito parcial para obtenção do grau de Mestre pelo Programa de PósGraduação em Administração de Empresas da PUC-Rio. Aprovada pela Comissão Examinadora abaixo assinada.

Prof. Marcus Wilcox Hemais Orientador Departamento de Administração - PUC-Rio

Prof. Luis Alexandre Grubits de Paula Pessôa Departamento de Administração - PUC-Rio

Prof ${ }^{a}$. Denise Franca Barros Universidade do Grande Rio

Prof. Leonardo Lima Gomes Departamento de Administração - PUC-Rio

Profá. Mônica Herz Vice-Decana de Pós-Graduação do CCS - PUC-Rio Rio de Janeiro,17 de abril de 2017. 
Todos os direitos reservados. É proibida a reprodução total ou parcial do trabalho sem autorização da universidade, do autor e do orientador

\section{Luiz Felipe Feltrim Julio}

Economista, pelo IBMEC RJ, com MBA em Management pela PUC Rio, MBA Internacional pela Católica Porto Business School e Mestrando em Administração pela PUC Rio. Trabalhou na área financeira de grandes empresas, como Kraft Food (Mondelez), Novartis e Tim Brasil. Atuou como gerente de negócios no Grupo Fleury, se especializou na gestão de serviços, especialmente no setor de Saúde.

Ficha Catalográfica

\begin{tabular}{|c|}
\hline Julio, Luiz Felipe Feltrim \\
Simbolismos associados ao serviço de \\
saúde suplementar por consumidores de baixa \\
renda / Luiz Felipe Feltrim Julio ; orientador: \\
Marcus Wilcox Hemais. -2017 . \\
68 f. : il. color. ; $30 \mathrm{~cm}$ \\
Dissertação (mestrado)-Pontifícia \\
Universidade Católica do Rio de Janeiro, \\
Departamento de Administração, 2017. \\
Inclui bibliografia \\
1. Administração - Teses. 2. Plano de \\
saúde. 3. Baixa renda. 4. Saúde suplementar. 5. \\
Comportamento do consumidor. 6. Consumer \\
Culture Theory. I. Hemais, Marcus Wilcox. II. \\
Pontifícia Universidade Católica do Rio de Janeiro. \\
Departamento de Administração. III. Título.
\end{tabular}

CDD: 658 


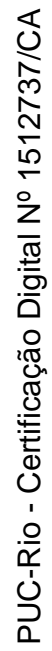

Às minhas três Marias. 


\section{Agradecimentos}

Primeiramente ao meu orientador Marcus Wilcox Hemais, pela incansável ajuda e inspiração. Marcus é um exemplo a ser seguido, dentro e fora da sala de aula. Dividiu comigo minhas angústias e me deu valiosos conselhos, seja para o ambiente acadêmico ou fora dele.

Aos professores Denise Barros e Luís Pessôa pela disponibilidade e gentileza em se tornarem parte deste objetivo. Sua participação consolida a busca de uma realização pessoal, um desejo que não tinha sido cumprido anos atrás. Muito obrigado.

Ao meu pai, Luiz Fernando e minha irmã Gisela que tanto me incentivaram a concluir mais essa etapa, sem a ajuda de vocês tudo teria sido muito mais difícil.

Aos meus colegas de turma da PUC-Rio pelas amizades, risadas e histórias. Agradeço também poder ter aprendido com a experiência de cada um de vocês.

Aos meus amigos de longa data, Igor, João e Rodrigo que entenderam e adiaram inúmeras vezes nossos jantares devido aos compromissos do mestrado.

À Carol, minha esposa, amiga e companheira, por me apoiar nos meus estudos. Você sempre acreditou que o esforço vale a pena, me incentivando nos momentos mais difíceis e por diversas vezes ter se desdobrado para ficar com nossas filhas enquanto eu estava ocupado com o Mestrado. Muito obrigado. Te amo.

Às minhas duas filhas, Maria Fernanda e Maria Clara, inspirações para mim, tenho muito orgulho de vocês. 


\section{Resumo}

Julio, Luiz Felipe Feltrim; Hemais, Marcus Wilcox. Simbolismos associados ao serviço de saúde suplementar por consumidores de baixa renda. Rio de Janeiro, 2017. 68p. Dissertação de Mestrado Departamento de Administração, Pontifícia Universidade Católica do Rio de Janeiro.

O mercado da saúde privada no Brasil vem se transformando nos últimos anos. Ao mesmo tempo que se observou um importante crescimento do número de vidas atendidas por planos de saúde privados, houve também uma concentração de mercado em operadoras e prestadores de serviço de saúde. O crescimento no número de vidas cobertas por planos privados de saúde teve em seu principal motivo uma penetração nas camadas da população de média e baixa renda, motivados tanto pela formalização do emprego, por ser o "Plano de Saúde" como um dos principais benefícios concedidos pelo empregador, como também pelo aumento real da renda do trabalhador, por meio da qual ele também passa a adquirir um plano de saúde. Considerando a notoriedade de que a saúde pública brasileira carece de um melhor atendimento, não sendo a primeira opção entre os portadores de planos de saúde, esse estudo exploratório teve o intuito de analisar os simbolismos associados ao serviço de saúde suplementar por consumidores de baixa renda. Para isso, foram realizadas 21 entrevistas em profundidade com consumidores de baixa renda que possuem ou possuíram planos de saúde. A análise dos dados discute os sentimentos e simbologias associados à posse de um plano de saúde e seu status social associado ao plano de saúde, a valorização das empresas que oferecem planos de saúde entre seus benefícios corporativos e a comparação entre os planos de saúde e os serviços públicos de saúde. A partir de tal análise, foi possível chegar a algumas conclusões.

\section{Palavras- chave}

Plano de Saúde; Baixa Renda; Saúde Suplementar; comportamento do consumidor; Consumer Culture Theory. 


\section{Abstract}

Julio, Luiz Felipe Feltrim; Hemais, Marcus Wilcox. (Advisor). Symbolisms associated with the Supplemental Health Service by Low Income Consumers. Rio de Janeiro, 2017. 68p. Dissertação de Mestrado Departamento de Administração, Pontifícia Universidade Católica do Rio de Janeiro.

The private health market in Brazil has been changing in recent years. At the same time as there was a significant increase in the number of lives served by private health insurance, there was also a market concentration in private health plans and providers. The growth in the number of lives covered by private health plans had in its main motive a penetration in the layers of the population of middle and low income, motivated by both the formalization of employment, being the "Health Plan" as one of the main benefits granted by the employer, but also by the real increase in the worker's income, where he also starts to personally acquire health plan. Considering the notoriety that the Brazilian public health needs a better service, not being the first option among health plan holders, this exploratory study had the purpose of analyzing the symbolisms associated with the supplementary health service by low income consumers. For this, 21 in-depth interviews were conducted with low-income consumers who have or have had health insurance plans. Data analysis discusses the feelings and symbologies associated with the possession of a health plan and its social status associated to the health plan, the appreciation of the companies that offer health plans as one of their corporate benefits and the comparison between the private health plans and the Public health services. From this analysis, it was possible to reach some conclusions.

\section{Keywords}

Health Plan, Low Income; Supplementary Health; consumer behavior; Consumer Culture Theory. 


\section{Sumário}

1. Introdução 11

1.1. Objetivo final 13

1.2. Delimitação do estudo 13

1.3. Relevância do estudo 13

2. Referencial teórico 15

2.1. Consumer Culture Theory 15

2.2. Significado do Consumo para os consumidores de Baixa Renda no Brasil 22

3. Metodologia $\quad 29$

3.1. Tipos de pesquisa $\quad 29$

3.2. Seleção dos Entrevistados $\quad 29$

3.3. Procedimentos de Coleta de Dados 33

3.4. Procedimentos de Análise dos Dados 35

3.5. Limitações da Metodologia 35

4. Descrição e Análise dos Dados 36

4.1. Sentimentos e simbologias associados à posse de um plano de saúde

4.2. Valorização das empresas que oferecem planos de saúde entre seus benefícios corporativos

4.3. Comparação entre os serviços de saúde pública e saúde privada

5. Conclusões

5.1. Implicações gerenciais

50

5.2. Sugestões e recomendações para novas pesquisas

6 Referências Bibliográficas

7. Apêndices

7.1. Apêndice A - Classificação dos consumidores de baixa renda no Brasil

7.2. Apêndice $B-$ Roteiro de entrevistas com os consumidores 


\section{Lista de figuras}

Figura 1: Framework sintético da CCT 17

Figura 2: Estratificação econômica do Brasil 59

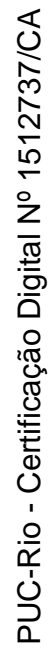




\section{Lista de tabelas}

Tabela 1: Perfil dos entrevistados 


\section{1.}

\section{Introdução}

O setor de saúde suplementar no Brasil tem se transformado na última década, tanto em tamanho e penetração, como pela profissionalização da gestão, que muitas vezes ainda é uma operação e gestão familiar (CANTALICE et al., 2011; BARBOZA, 2016; BICHUETTI, 2009; BAHIA, 2011; JUNIOR, 2014; PEREIRA, 2016).

De acordo com dados da Agência Nacional de Saúde Suplementar (2017), o número de cidadãos que tem algum tipo de cobertura privada para despesas de saúde vem aumentando nos últimos anos. No final de 2005, a quantidade de participantes era de 35,4 milhões de beneficiários. Em dezembro de 2016, esse número já alcançava 47,9 milhões de beneficiários. A média acumulada anual de crescimento nesse período foi de 2,6\%, maior que o crescimento populacional, que foi de $11 \%$, com uma média acumulada anual de crescimento de 1,05\% (INSTITUTO BRASILEIRO DE GEOGRAFIA E ESTATÍSTICA, 2017). A grande maioria desses usuários do serviço, cerca de 32 milhões, participa de planos coletivos empresariais, e o restante de planos individuais, familiares ou coletivos por adesão, sendo estes formados por sindicatos e associações.

Esse crescimento de beneficiários é atribuído a alguns fatores, tais como o aumento da renda das famílias, taxa de atividade econômica e, principalmente, o aumento dos trabalhadores com carteira assinada (INSTITUTO DE ESTUDOS DE SAÚDE SUPLEMENTAR, 2013).

Apesar de tamanho crescimento em 10 anos, verificou-se que nos últimos dois anos, de dezembro de 2014 para dezembro de 2016, houve uma diminuição da base de beneficiários, atribuída à desaceleração econômica que o Brasil tem passado. Dados mostram que, nesses dois anos, mais de 2,5 milhões de residentes no Brasil deixaram de possuir planos de saúde (VILLELA, 2016; AGÊNCIA NACIONAL DE SAÚDE SUPLEMENTAR, 2017). Essa retração econômica, com a diminuição do emprego formal e, consequentemente, uma perda de trabalhadores com carteira assinada, pode estar levando a uma retração do número de vidas cobertas por tais planos privados (CUNHA, 2015; CARNEIRO et al., 2016). 
Outro fator de importante impacto no setor foi a inflação da saúde, medido pelo Instituto de Instituto de Estudo de Saúde Suplementar (2016), que expressa a variação do custo das operadoras de planos de saúde. Esse índice foi de 19,3\% no acumulado de janeiro a dezembro de 2015, frente ao índice de inflação do governo, IPCA, que refletiu um aumento de $10,7 \%$ neste mesmo período.

Esse efeito também refletiu no custo do benefício de saúde sobre o total da folha de pagamentos das empresas, que passou de $10,4 \%$ do total do custo com pessoal em 2009 para 11,5\% em 2015, refletindo um maior dispêndio das firmas com custeio de benefícios em saúde para seus funcionários.

Entre os beneficiários que perderam seus planos de saúde estão consumidores de baixa renda (ELIAS, 2016), que outrora chegaram a representar uma grande parcela de segurados das operadoras privadas (NIERO, 2013). Para esses indivíduos, os planos representam uma possibilidade de fugir do Sistema Único de Saúde (SUS), considerado de qualidade significativamente insatisfatória (CARAZZAI, 2008).

Consumidores de baixa renda no Brasil têm sido considerados um dos principais propulsores do crescimento econômico da última década, devido ao aumento do seu poder de compra (SOUZA; KACHUBA, 2015). Embora no passado somente tivessem condições de consumir itens de necessidade básica, esse quadro mudou desde o advento do Plano Real e a estabilização econômica e da inflação brasileira, quando esse segmento passou a consumidor, cada vez mais, produtos e serviços de diversas naturezas (NOGAMI; VIEIRA; MEDEIROS; 2015). Entre os serviços consumidos por esses consumidores nesse período estão planos de saúde.

Apesar de sua importância, a literatura de marketing pouco discute a relação entre consumidores de baixa renda e planos de saúde, de forma que há escasso conhecimento sobre quais são os significados que esses indivíduos atribuem ao serviço. O presente estudo, portanto, tem como foco trazer luz a essa questão sobre a ótica da teoria da cultura do consumo, a Consumer Culture Theory. 


\section{1.}

\section{Objetivo final}

O presente estudo tem como objetivo entender os significados atribuídos por consumidores de baixa renda a planos de saúde. Para alcançar tal objetivo, foram realizadas entrevistas em profundidade com 21 consumidores de baixa renda, que possuíam ou já possuíram planos de saúde.

\section{2.}

\section{Delimitação do estudo}

Entre as delimitações do estudo, pode-se destacar que este trabalho se volta mais especificamente para estudar os consumidores de baixa renda de planos de saúde oferecidos na cidade do Rio de Janeiro.

Por se tratar de um estudo cujo foco é entender o comportamento dos consumidores de baixa renda, não se pretende fazer uma análise das empresas operadoras dos planos de saúde.

Ademais, embora existam diferentes formas de pesquisar o comportamento do consumidor em marketing, pretende-se fazê-lo, no presente caso, por meio da ótica da linha interpretativista de Consumer Culture Theory (CCT).

\section{3.}

\section{Relevância do estudo}

Como justificativa para o presente trabalho, percebem-se que pode trazer contribuições para os meios acadêmico e empresarial. Para o segmento acadêmico, a contribuição se dá por preencher uma lacuna pouco explorada na literatura de marketing no Brasil. Embora existam autores (HEMAIS; CASOTTI, 2015) que toquem em discussões sobre consumidores de baixa renda e a sua relação com planos de saúde e estudos que mostrem os significados atribuídos por consumidores de baixa renda a diferentes produtos e serviços (LIVRAMENTO et al, 2013; OLIVEIRA; SILVA; FILHO, 2016), nenhuma pesquisa foi encontrada abordando o objetivo aqui buscado.

No âmbito empresarial, a importância do estudo é trazer mais conhecimento para operadoras de planos de saúde quanto à importância, sentimentos e 
simbologias que o segmento de baixa renda associa a esses planos. Isso permite entender qual é o nível de prioridade atribuído ao serviço em detrimento de gastos com outras despesas particulares ou de outros benefícios corporativos. Isso possibilita a tais empresas mais bem planejar as formas de criar e comercializar tais planos, adequando-os de forma mais atrativa para o público em questão.

Adjacente aos pontos expostos acima, este estudo utiliza-se de informações de mercado, pois o pesquisador tem experiência no setor e, portanto, pôde contribuir com seu conhecimento e acesso às empresas e atores deste mercado, quais um pesquisador puro não teria acesso e, com isso, enriquecer a discussão e análise do mercado estudado. 


\section{2. \\ Referencial teórico}

Neste capítulo, são abordadas as bases teóricas do estudo. Inicialmente, discute-se a teorização sobre cultura do consumidor, mais conhecida como Consumer Culture Theory. A segunda parte apresenta discussão sobre o comportamento dos consumidores de baixa renda e os significados que atribuem a determinados objetos de consumo.

\section{1 .}

\section{Consumer Culture Theory}

Consumer Culture Theory é uma linha de estudos dentro de comportamento do consumidor que tem sido amplamente estudado nas últimas décadas (DOUGLAS; ISHERWOOD, 2009; MCCRACKEN, 2003; MATTOSO, 2010; ROCHA, 2005). É uma tradição de pesquisa interdisciplinar, que analisa a cultura do consumidor, gerando resultados empiricamente fundamentados e inovações teóricas, que são relevantes para um amplo eleitorado, que abrange desde acadêmicos de disciplinas das ciências sociais a formuladores de políticas públicas e empresários (ARNOULD; THOMPSON, 2005).

Utiliza-se o termo "cultura do consumo" para descrever um sistema interligado de imagens, textos e objetos comercialmente produzidos, que determinados grupos fazem uso para, através dos significados e identidades, terem um sentido coletivo dos seus ambientes, orientando experiências e vidas dos seus membros (KOZINETS, 2001). O estudo da compreensão do consumo passa pelas escolhas comportamentais e as práticas sociais dos consumidores.

Essa visão sobre o consumo difere de outras anteriormente estudadas, que se baseavam, predominantemente, na psicologia e nos aspectos econômicos na decisão de compra dos indivíduos (ARNOULD; THOMPSON, 2005). Essas linhas de estudo deduziam que toda compra envolve uma escolha, com base na função de maximização da utilidade, permitindo ao consumidor ter um maior retorno com base nos recursos disponíveis (CHAUVEL, 2000).

Por outro lado, em CCT o consumo não se restringe a aspectos funcionais, que atendam necessidades individuais; na verdade, o consumo se dá pela escolha 
dos significados inseridos em determinados objetos, interpretados de certa forma por um grupo ao qual o indivíduo quer pertencer (ARNOULD; THOMPSON, 2005). Nessa linha, diversos aspectos do consumo são resultados de uma trama de representações e classificações em um esquema simbólico traduzindo seus significados obtidos através do consumo (BARROS; MATTOSO, 2007).

Nessa linha, Rocha (2005) indica que:

O consumo é um sistema de significação e a verdadeira necessidade que supre é a simbólica. (...) O Consumo também é como um código e por ele são traduzidas muitas das nossas relações sociais, meio do qual podemos comunicar significados (...) de forma a transmitir mensagens.

Pode-se, então, assumir que os bens que um indivíduo possui são, também, indicativos de relações sociais, permitindo classificar coisas e pessoas, produtos e serviços, indivíduos ou grupos (ROCHA, 2005). Por ser a parte visível da cultura, a primeira função dos bens é fazer um determinado consumidor ter um envolvimento com um grupo de consumidores e/ou com a sociedade à qual ele pertence ou deseja pertencer (DOUGLAS; ISHERWOOD, 2009).

Os significados simbólicos de consumo, que estão presente em marcas, propagandas e no próprio uso dos bens de forma abrangente, são modificados continuamente, bem como o modo de interação entre consumidores e empresas. Essas relações entre os ambientes social e cultural, a forma da empresa interagir com seus consumidores e vice-versa e a alteração e distribuição dos significados do consumo foram, e ainda estão sendo, exploradas por diversos pesquisadores (GAIÃO; SOUZA; LEÃO, 2012).

Em seu estudo seminal, Arnould e Thompson (2005) discutem quatro grandes linhas de pesquisa em CCT, sintetizadas por Gaião, Souza e Leão (2012) na Figura 1, a seguir: 
Figura 1: Framework sintético da CCT

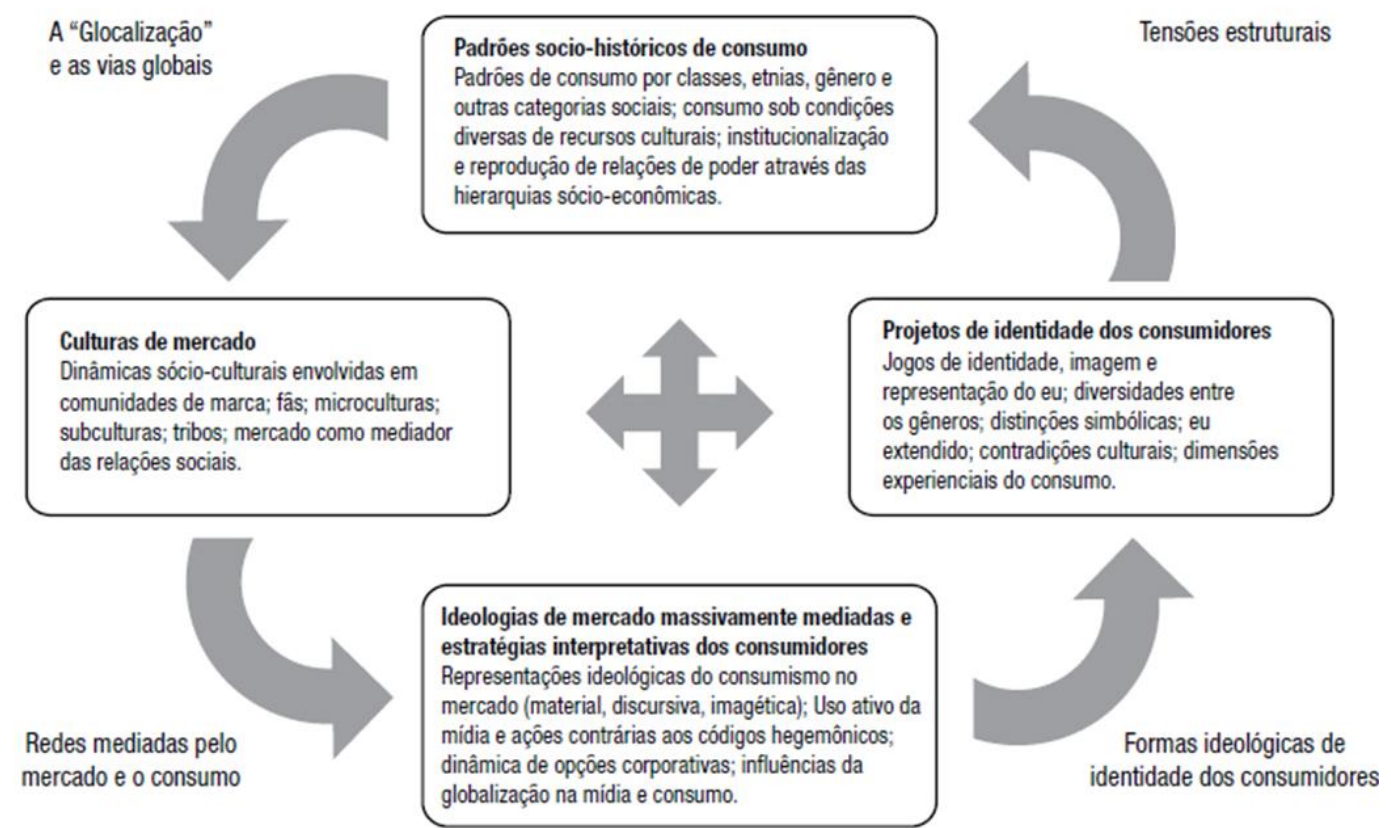

Fonte: Arnould e Thompson (2007), adaptado por Gaião, Souza e Leão (2012)

A primeira dimensão "Projetos de identidade dos consumidores" é a qual os consumidores transformam o conteúdo dos bens e serviços gerados pelo mercado em uma forma simbólica, geralmente via propaganda e, com isso, traduzem e constroem uma posição de consumo, em uma narrativa de identidade, transformando o consumo em uma forma de representação.

$\mathrm{Na}$ segunda dimensão, "Padrões sócio-históricos de consumo", retrata-se que as decisões de consumo são influenciadas por "padrões" criados por etnias, gêneros, classes sociais, famílias e outros grupos formais, relacionando estes padrões com a experiência de consumo.

A terceira dimensão, "Culturas de mercado", cita o consumidor como produtor de cultura em um ambiente de interesse comum de consumo, como estilo de vida e ocupações de lazer, de forma que se solidarizam e se identificam coletivamente.

A quarta dimensão, "Ideologias de mercado massivamente mediadas $e$ estratégias interpretativas dos consumidores", analisa como a globalização econômica e cultural afeta os projetos de identidade do consumidor dentro de 
contextos sociais específicos, discorrendo sobre como o mercado transforma ideias culturais em atributos para produtos e serviços, de forma que possa se utilizar dessa ideologia do consumidor para guiar experiências dos consumidores para fins comerciais. (ARNOULD; THOMPSON, 2005, 2007; GAIÃO, SOUZA; LEÃO, 2012; PINTO; FREITAS; JOAQUIM, 2015).

Essas novas abordagens para interpretar o consumo, que tendem a ser mais consistentes e próximas à realidade, são experimentadas em diferentes ambientes econômicos, contribuindo para a análise e o entendimento das questões do consumo na sociedade atual, que está cada vez mais informada, interligada e multidisciplinar.

Para McCracken (2003), o significado cultural dos bens de consumo está constantemente em trânsito, alimentado pela ajuda de diversos esforços coletivos e individuais, por meio de designers, produtores, publicitários e consumidores. Esse movimento ocorre quando o significado cultural é absorvido pelo mundo culturalmente constituído, que é transferido para um bem de consumo e que, por sua vez, chega ao consumidor individual.

O mundo culturalmente constituído determina como os fenômenos de crenças e pressupostos de uma cultura são apreendidos e assimilados nos bens de consumo. Esses, por sua vez, são segmentados, de forma a serem consumidos distintamente (ou, até, exclusivamente) por indivíduos de diferentes classes sociais, gênero, idade e ocupação. Outra forma de segmentação ocorre em função de características culturais de tempo, espaço e natureza. Todos esses elementos ajudam a formar diferentes categorias de consumo para os bens.

A transferência do significado cultural para os bens de consumo ocorre por meio tanto da publicidade, quanto do sistema de modas. No que se refere à primeira, busca-se transferir os significados culturais do mundo culturalmente constituído a um bem de consumo, utilizando-se de mídias de comunicação para tangibilizar essa transferência.

Já o sistema de moda atua em três modos diferentes para transferir significados aos bens. A primeira forma é por meio da mídia formal (em jornais e revistas, por exemplo), associando os bens a categorias e princípios culturais. A 
segunda maneira de transferência de significado ocorre quando se associa bens com personalidades, principalmente celebridades e líderes de opinião. O terceiro modo é percebido quando há uma mudança radical na sociedade; geralmente, pessoas à margem da sociedade se posicionam contra as categorias e os princípios culturais já estabelecidos, agindo de forma totalmente inovadora, como fizeram os punks e os hippies em suas épocas, por exemplo (MCCRACKEN, 2003).

Dessa forma, pode-se afirmar que bens de consumo carregam, mesmo que ocultamente, um significado cultural, que pode ou não ser percebido pelo consumidor. Em geral, a percepção é mais clara quando há uma subtração do bem, decorrente, por exemplo, de um roubo ou um despojamento (BELK, 1988).

Por fim, o modelo de McCracken (2003) preconiza que ocorre a transferência do bem para o consumidor. Segundo o autor, o significado cultural do bem de consumo é transportado para o consumidor individual por quatro rituais. Os rituais de troca ocorrem quando bens carregados de significados culturais são oferecidos de um indivíduo a outro, na forma de presentes. Geralmente, um doador escolhe um presente pois acredita que tal bem possui propriedades culturais significativas que deseja transferir.

Os rituais de posse ocorrem quando os indivíduos atribuem status e significados dos bens de consumo como balizadores de categorias culturais, como a celebração de uma nova casa ou quando se fotografa uma nova aquisição, objetivando, assim, a transferência das qualidades dos bens para seu dono. Mas, há também os bens que os donos possuem, mas nunca reivindicam, pois, seus atributos simbólicos não aspiram sucesso, criando um paradoxo, no qual o consumidor possui sem possuir.

Há também os rituais de arrumação, tais como os processos de se arrumar para sair ou arrumar sua residência, seu carro e demais itens, pelos quais se despende quantidade de esforço e energia imensamente redundantes, a fim de que esse objeto possa fornecer propriedades realçadas para seu dono, transferindo, portanto, a propriedade simbólica dos bens e transferi-los para o consumidor.

E, por fim, os rituais de despojamento que ocorrem quando é adquirido algo já usado, como uma casa ou carro e, para isso, o novo dono usa um ritual para 
apagar o significado de pertencimento ao dono anterior. O contrário também ocorre quando o dono está prestes a se desfazer de algum bem, então faz-se um ritual de apagar o significado que outrora fora investido em determinado bem, evitando, assim, o contato com as propriedades significativas do dono anterior, bem como "libertar" o significado de posse e reivindicá-lo para si (MCCRACKEN, 2003).

O entendimento do processo de transferência de significados, tanto do mundo para o bem, como do bem para o indivíduo, permite uma melhor compreensão das influências dos processos de consumo e seus significados culturais, ampliando o entendimento sobre o consumidor e suas considerações na sua decisão de consumo.

Quando os consumidores fazem escolhas de quais bens irão consumir, estão criando, de forma contínua, certos padrões de discriminação, trazendo para os bens uma parte visível da cultura, utilizando os bens como um comunicador cultural (DOUGLAS; ISHERWOOD, 2009). Esses atos de consumo atingem várias dimensões, tais como aspectos culturais e simbólicos, satisfazendo distintos interesses no consumo, entre eles valores sociais e morais, fazendo com que os indivíduos também passem a serem julgados e compreendidos pelas escolhas de consumo que fazem, e pelas escolhas de suas posses (BELK, 1988).

Belk (1988) discorre entre a distinção do self (eu) e do self estendido (meu) que se faz relevante por apresentar de forma pioneira que o consumo ajuda os indivíduos a definir quem são. A partir dessa perspectiva, passa-se a olhar o comportamento do consumo como a compreensão do significado que os consumidores atribuem aos bens.

O self representa a identidade do indivíduo, o que considera como o seu “eu”. Já o self estendido é o que o indivíduo considera como próprio, como sendo "seu", incluindo o que tem um significado emocional para o portador, ou seja, a soma de tudo que as pessoas reconhecem como sendo proprietária. A escolha dos bens que cada indivíduo possui e ostenta contribui para a sua autoimagem, sendo essa a extensão do "eu”, ou seja, o self estendido (MOREL et al., 2016). 
A posse dos bens e a decisão de consumo podem ser tratadas de outras formas, não apenas como bens materiais adquiridos, mas também como o acumulo de dinheiro, ter animais, sinais particulares em parte do corpo ou, até mesmo, ter a "posse" de outras pessoas, evidenciando relações entre essas posses e o "eu" do indivíduo (BELK, 1988). Por vezes, o significado cultural embutido nos bens é percebido pelo consumidor individual, reconhecendo o significado do bem apenas em condições excepcionais, como por perda, roubo ou despojamento.

O estudo dos elementos culturais e sociais pertencentes nos bens quando analisado sob a ótica do CCT mostra que o consumo é um processo essencialmente cultural por alguns fatores. Primeiramente, é um processo pois não se inicia nem se esgota na aquisição do bem ou serviço. Segundo, como a aquisição de bens e serviços é um elemento de afirmação e construção de identidade, exclusão e inclusão social que rege as relações sociais, vê-se que o consumo do indivíduo é tido como um efeito cultural (CASTILHOS, 2007).

A sociedade contemporânea, no extrato social que o indivíduo pertence, não mais dita a forma, a priori, da identidade individual, pois cada vez mais o indivíduo faz as suas próprias escolhas. O fato de uma pessoa nascer muito rico ou muito pobre não mais a obriga a se vestir de uma determinada maneira, de andar por determinada calçada ou onde sentar-se, por exemplo, mas sim, o indivíduo é diferenciado por uma série de mecanismos, como classes sociais, gênero, idade, entre outros, que acabam influenciando quais tipos de consumo são mais apropriados para cada indivíduo (CASTILHOS, 2007).

Nesse sentido os consumidores tomam emprestado o que cada produto ou serviço representa socialmente e, com essas representações, os indivíduos constroem mentalmente seus significados com suas experiências pessoais ou de um determinado grupo. Esse processo de absorção do significado do produto ou serviço pelo indivíduo ou por um grupo faz parte de uma interação social que os consumidores se propõem (CRUZ, 2008).

$\mathrm{O}$ ato de fazer compras também pode gerar prazer. Dependendo do indivíduo e também da sua classe social, o simples ato de ir ao supermercado e levar os produtos desejados e importantes para o indivíduo pode gerar um sentimento positivo de prazer e recompensa, com caráter lúdico e fonte de 
autossatisfação e, por outras vezes, de frustração se, por exemplo, não puder adquirir um bem desejado. Esses sentimentos, como os de prazer e frustação, atravessam os vários tipos de consumidores, em distintas classes sociais, com orçamentos mais restritos ou não (CHAUVEL; MATTOS, 2008).

\section{2.}

\section{Significado do Consumo para os consumidores de Baixa Renda no Brasil}

Consumidores de baixa renda não despertavam interesse do meio empresarial até o advento do Plano Real, ocorrido a partir de 1994. Esse fato não foi exclusivamente brasileiro, já que $75 \%$ das vendas mundiais dos fabricantes de bens de consumo eram direcionados para as classes média e alta dos países desenvolvidos (CHAUVEL; MATTOS, 2008).

No Brasil, o crescimento do consumo na base da pirâmide se deu por vários fatores, entre eles o controle da inflação, os programas de transferência de renda, a queda do desemprego com a formalização do trabalho, aliado ao crescimento econômico, a retomada dos investimentos públicos e também pela expansão do crédito (MEIRELES, 2014; SOUZA; KACHUBA, 2015).

A expansão do crédito na base da pirâmide foi responsável por parte do crescimento do consumo para a baixa renda. $\mathrm{O}$ crédito pôde ser acessado de duas maneiras, a primeira por meio de empréstimo (crédito na forma de dinheiro) que deve ser evitada, por ser considerada uma forma de comportamento anormal, já que o correto seria ter o dinheiro para poder realizar a despesa. A outra maneira é o crédito para consumo (como boletos ou carnês de crediários), tais como obrigações geradas por lojas a partir da aquisição de algum bem. Nesse caso, o crédito é mais aceitável pois houve um planejamento financeiro e um compromisso para sua quitação (PONCHIO; ARANHA, 2007).

O estudo de Gerhard et al (2015), sobre a influência dos valores de compra hedônico e utilitário no endividamento dos consumidores de baixa renda, mostrou que indivíduos com baixo poder aquisitivo se endividam, principalmente, por configurar uma dimensão hedônica da compra, já que os desejos de consumo, que são fatores subjetivos, variam de acordo com o contexto de cada um. Mesmo com 
restrições de recursos, acesso mais difícil a informação e baixo nível de escolaridade, a racionalização da escolha contempla não apenas o preço mais baixo de um produto ou serviço, mas a distância da sua residência, o tipo de produto encontrado, disponibilidade de crédito, entre outros aspectos (GROSSI; MOTTA; HOR-MEYLL, 2008).

Todavia, o aumento do poder de compra desses indivíduos atrelado a estabilidade inflacionária fez com que o meio empresarial passasse a vislumbrar importantes ganhos com esse estrato social e, atualmente, tanto empresários, quanto acadêmicos, mostram interesse em entender esses consumidores (ROCHA; SILVA, 2009).

Prahalad e Hammond (2002) destacam que os hábitos de consumo dos indivíduos de baixa renda são diferentes dos hábitos de consumo das classes mais abastadas, tanto em países desenvolvidos, como nos emergentes. Esta segmentação de consumo sugere que qualquer empresa que queira comercializar produtos e ou serviços para consumidores de baixo poder aquisitivo deve ter que fazer modificações significativas em seus produtos e serviços. Nesse momento, tornou-se importante direcionar estratégias de mercado para esse público e respeitar as diferenças entre os distintos grupos que compõem essa classe social.

Contudo, a comercialização de produtos e serviços para consumidores de baixa renda não deve consistir em apenas adaptar às estratégias de vendas, marcas e produtos previamente existentes a esse novo mercado, mas sim de um desenvolvimento de estratégias voltadas e direcionadas para esse segmento de mercado. Nessa linha, Rocha e Silva (2009) afirmam que:

Trata-se de não apenas vender para os pobres, mas em desenvolver produtos e serviços que atendam suas necessidades ao menor custo possível, com condições de crédito justas e atendimento digno. Trata-se, ainda, de dispor de empregados satisfeitos, que atendam bem seus clientes, porque eles mesmos se sentem felizes com a empresa, com seus salários e com as condições de trabalho que lhes são oferecidas.

Antes de empresas se engajarem em realizar as modificações necessárias para vender seus produtos e serviços aos consumidores de baixa renda, faz-se necessário entender quem são e o que desejam esses indivíduos (ROCHA, 2009). No passado, pesquisas de mercado praticamente excluíam esse segmento de 
qualquer levantamento, de forma que o empresariado conhece limitadamente quem são esses consumidores (BARROS, 2006).

Conhecer o consumidor, seus hábitos, práticas e lógicas de consumo e entender qual é a importância que determinadas marcas representam no seu cotidiano são informações fundamentais para as empresas crescerem nesse mercado. O consumo de um determinado produto ou serviço não, necessariamente, espelha a renda do indivíduo, pois o consumo, para todas as sociedades, é um sistema de medição e reprodução social, caracterizado pelo contexto sociocultural que influencia diretamente o consumo das camadas populares (BARROS; ROCHA, 2007).

O estudo de Barros (2006) evidenciou que consumidores de baixa renda mostram um grande desejo de participar dos benefícios da sociedade de consumo, de modo que, ao consumir, sentem que estão se distinguindo de outros indivíduos da mesma classe social, aproximando-se do "mundo dos ricos". O consumo é compreendido como um processo dinâmico, que é influenciado mutuamente por diferentes grupos e repleto de significados culturais, perfazendo a hierarquia de escolhas em uma base cultural e simbólica que os indivíduos têm no momento de consumir.

Essa hierarquia de escolhas foi constatada em pesquisa realizada por Barros e Rocha (2007), onde os autores relataram que a escolha da marca de determinados produtos pode variar, a depender da situação em que esses serão consumidos. Quando o consumo é feito de maneira privada, uma marca mais barata pode ser consumida, mas quando o consumo é feito publicamente, marcas melhores são apresentadas. Nessa mesma pesquisa, os autores citam que certas marcas aspiracionais, pertencentes ao mundo dos ricos, são eventualmente compradas por pertencerem aos sonhos de consumo, capturando um sinal de status social.

Os bens de consumo trazem significados, simbolizando um status social do indivíduo ou da família e ajuda a segregar, dentro da classe de mais baixa renda, hierarquias de consumo, como os pobres-pobres, os pobres e a elite dos pobres. O principal elemento de segregação é a moradia, que é tida como o símbolo de estabilidade e de continuidade (CASTILHOS, 2007). 
Yaccoub (2011) identificou que mesmo em regiões menos favorecidas, há indivíduos ou famílias que dispõem de renda superior a diversas famílias de bairros mais favorecidos de grandes metrópoles brasileiras, mas que não se viam como elite quando comparados a outros grupos de fora de seu cotidiano. Quando eram comparados a outros moradores de seu bairro, eles se viam como elite, pois demonstravam adquirir bens e serviços que representavam um status social superior, como residir em uma casa melhor, ter o filho estudando em escolas particulares, viajar, etc.

Estes indivíduos, mesmo com condições de renda para poder morar em bairros ou municípios mais nobres, que apresentam maiores ofertas de serviços e uma melhor infraestrutura, preferem permanecer no local de origem, pois lá se destacam pelo poder aquisitivo e não teriam a mesma importância em bairros ou municípios de maior poder aquisitivo (YACCOUB, 2011).

Além da moradia, outros itens conferem status social aos indivíduos de baixa renda que são, entre outros, os eletrodomésticos, onde as famílias se destacam pela qualidade e quantidade de itens disponíveis em casa. Os móveis também carregam seus símbolos, mas em diferentes contextos. Já outros bens como os aparelhos eletrônicos carregam o simbolismo de modernidade e prosperidade, que atribuem status aos seus donos e, por isso, são expostos nas residências. Todavia, todos devem ser novos, pois bens que são fruto de doação ou comprados usados não são percebidos como diferenciadores de status (CASTILHOS, 2007).

A posse dos bens não implica, necessariamente, em mobilidade social, ou seja, em uma elevação de classe social, mas sim em uma melhora da condição de vida em relação a eles próprios, onde é o "vizinho" e não o rico, o espelho do seu dia-a-dia e podendo assim, estabelecer uma comparação entre os padrões de vida que tem versus os que os outros próximos também tem. A comparação não é feita apenas com os bens materiais adquiridos, mas também com a sua conduta, os serviços que utiliza e a forma de influência que o indivíduo tem na sociedade que participa (CASTILHOS, 2007).

A valorização de determinados bens para algumas pessoas, muitas vezes itens supérfluos, são sinalizadores de hierarquia social e qualidade. As roupas, que 
são utilizadas como uma espécie de camuflagem e de inserção em determinados grupos sociais, são, geralmente, mais significativos aos mais jovens, apresentando uma alusão ao afastamento da pobreza (ROCHA; SILVA, 2008).

Os alimentos, por sua vez, traduzem um importante papel simbólico na segregação de outros grupos sociais, especificamente no que diz respeito à sua qualidade e quantidade que se tem em casa. (ROCHA; SILVA, 2008).

A ideia de que o consumidor de baixa renda somente se importava com o preço do produto, deixando de lado outros atributos, tais como qualidade, local de venda, design, atendimento, marca, tornou-se equivocada (SILVA; PEREIRA, 2011). Essa percepção induzia as empresas à ideia de que consumidores de baixa renda tinham como critério para a compra o custo que o bem lhes traria, deixando de considerar os valores que os produtos de marca carregavam.

Estar bem informado sobre produtos e marcas é importante para que a camada de baixa renda possa ter uma mobilidade entre as camadas sociais e seu entorno, adotando certos tipos de consumo e rejeitando outros, com o intuito de se diferenciar de classes mais baixas e se definindo como um grupo distintos do demais (SOUZA; AYROSA; CERCHIARO, 2013).

A marca é um importante sinalizador de qualidade e hierarquia social e tem grande importância para os consumidores de baixa renda. A marca não é apenas valorizada em itens de moda, mas também em itens alimentícios e escolares, servindo de elementos de distinção intraclasse, por oferecer prestígio e também ser vista como um indicador de afeto (BARROS; ROCHA, 2007).

Embora a marca seja importante, o preço do bem é também uma consideração relevante na escolha de consumidores de baixa renda em suas compras. A preocupação com o deslocamento até o local de consumo, o ambiente da loja e o valor dos desembolsos unitários são fatores decisivos nesse processo. A experiência da compra, passa pelo ambiente da loja, pela disposição dos produtos nas prateleiras, combinado com uma variedade de mercadorias expostas, que acaba por transmitir uma imagem de fartura, bem-estar e de satisfação na compra. Essas sensações tornam-se formadores de valores e símbolos, sendo aptos 
a transformar as atitudes dos clientes perante o ato da compra (PARENTE; BARKI; KATO, 2005).

Tais atitudes podem ser vistas, por exemplo, nas compras domésticas realizadas por esses indivíduos, pois, além de fazer compras mensais, vão ao supermercado, aproximadamente, 15 vezes por mês, gastando pouco a cada ida e variando o local de consumo (PARENTE; BARKI; KATO, 2007).

Essas idas constantes aos mercados mostram que a busca por produtos de preços mais baratos são importantes a esses consumidores, porque é comum que acabem pagando mais caro pelos produtos que classes sociais mais favorecidas, pois têm poucas condições de deslocamento para os locais que oferecem produtos mais baratos (PARENTE; BARKI; KATO, 2005).

Prahalad e Hart (2002) argumentam que o consumidor de baixa renda é estimulado a comprar produtos de marca pois não teriam condições de comprar novamente o mesmo produto caso algo dê errado. Por isso, buscam produtos conhecidos e/ou de melhor qualidade. Adquirir marcas conhecidas é uma estratégia de redução de riscos, justificada para não desagradar a família e garantir que o gasto vá resolver seus problemas. Caso contrário, a compra não pode ser desfeita, além de consumidores de baixa renda terem vergonha de retornar à loja onde adquiriram o produto e pedir para trocar (GROSSI; MOTTA; HORMEYLL, 2008).

Como em vários outros mercados, consumidores de baixa renda querem ser bem atendidos, adquirir produtos de qualidade e, mesmo com uma renda mais baixa, estão dispostos a pagar um preço mais alto para levar um produto de uma marca reconhecida ou usufruir de um serviço diferenciado. Por outro lado, estes consumidores apresentam baixa autoestima e são leais a marcas (BARKI; PARENTE, 2010).

Nessa linha, o varejista deve criar propostas de valor para ter outras maneiras de conquistar o consumidor de baixa renda, sem ser, necessariamente, com foco específico em preço baixo, mas com características em que o consumidor de baixa renda projete seus anseios em um nível superior ao seu (GIOVINAZZO, 2003). 
Já para os produtos e serviços de beleza, Livramento, et al (2011) relataram que o status que tais produtos concedem são os principais motivos para a sua aquisição, além de fazerem-nas sentirem-se mais bonitas e confiantes, mesmo considerando seu restrito orçamento e limitações financeiras.

Em se tratando da compra de passagem aérea, o preço é o atributo mais significante, mas outros itens do componente de mix, como os programas de milhagem, nível de atendimento, conforto e pontualidade também impactam a decisão da compra da passagem para esse público (CHIOSINI et al., 2014).

Em se tratando de produtos culturais para esse segmento da população, o consumo está diretamente relacionado à influência dos grupos de referência e ao seu capital cultural, tornando-se determinante para a identidade dos consumidores e sendo uma forma de inclusão social e afirmação de identificação e igualdade com os consumidores deste extrato social (RABÊLO et al., 2014).

O consumo de cultura pelos indivíduos de baixa renda trouxe reflexos na programação de televisão no Brasil. Em 2012, a Rede Globo inseriu três novelas ('Cheias de Charme', 'Avenida Brasil' e 'Salve Jorge') na sua programação, nas quais abordava o contexto social e cultural de classes de baixa renda, com o intuito de aproximar a realidade sociocultural desse grupo social às realidades fictícias dessas tramas (CRUZ, 2014).

O curioso é que produtos e serviços destinados aos indivíduos de alta renda recebem tratamento publicitário com símbolos que representam a alta classe, já os produtos mais abrangentes, que podem atingir uma classe mais baixa, a publicidade não faz menção aos símbolos de uma classe menos favorecida, ou seja, não há um apelo direto de propaganda com símbolos de baixa renda, mesmo que a segmentação de determinado produto ou serviço sejam destinados às classes menos favorecidas (SILVA; PEREIRA, 2011). 


\section{3. \\ Metodologia}

Este capítulo discorre sobre as escolhas metodológicas adotadas para a pesquisa. Divide-se em cinco partes, que apresentam o tipo de pesquisa, a forma de seleção dos entrevistados, o procedimento adotado para a coleta de dados e a análise dos dados coletados e, por fim, as limitações da metodologia.

\section{1.}

\section{Tipos de pesquisa}

Embora existam estudos sobre significados atribuídos por consumidores de baixa renda a bens e serviços de consumo (CHIOSINI et al., 2014; NOGAMI; VIEIRA; MEDEIROS, 2012; YACCOUB, 2013) e pesquisas sobre o mercado de saúde suplementar (FERRAZ et al., 2008; GUIMARÃES et al., 2015; SILVA, 2014), não foram encontrados estudos específicos em marketing que abrangessem ambos os temas em conjunto. Dada essa escassez de informações, decidiu-se por realizar uma pesquisa exploratória, a fim de começar a entender o fenômeno em questão (CRESWELL, 2010; PIOVESAN; TEMPORINI, 1995).

Escolheu-se, também, por se utilizar uma abordagem qualitativa, por entender que essa linha de pesquisa traria informações mais precisas, ao permitir que os entrevistados expressem sua atitude e comportamento dentro de seu contexto (CRESWELL, 2010). Chikweche e Fletcher (2012) argumentam que pesquisas qualitativas com consumidores de baixa renda são mais adequadas do que as pesquisas quantitativas por apresentarem oportunidades destes consumidores em expressar seus sentimentos e pensamentos do seu dia a dia, o que dificilmente conseguiriam fazer caso participassem de uma survey.

\section{2.}

\section{Seleção dos Entrevistados}

Os participantes da pesquisa foram consumidores de baixa renda, que já utilizaram serviço de saúde suplementar e tiveram ou têm plano de saúde. Para garantir que os entrevistados soubessem responder corretamente a pesquisa, delimitou-se o seu perfil aos seguintes critérios: 
- Ser maior do que 18 anos;

- Ter feito uso de algum serviço de saúde privado (exame, consulta, internação, emergência, etc.) nos últimos 24 meses;

- Ter renda familiar mensal de até $\mathrm{R} \$ 8.800,00$ por mês (até 10 salários mínimos (com ano de referência em 2016);

- Possuir ou já ter tido um plano de saúde;

- Não ser empregado ou dependente de funcionário de operadoras de saúde, por poderem possuir conhecimento prévio qualificado sobre o serviço de saúde e contaminar a pesquisa.

Ainda existem divergências sobre como classificar quem é o consumidor de baixa renda no Brasil (NOGAMI; VIEIRA; MEDEIROS, 2012; ABREU; HORMEYLL; NOGUEIRA, 2015) e se o segmento da classe C pertencente a esse grupo ou faz parte do grupo de consumidores de uma "Nova Classe Média" (NERI, 2011). Diversos autores classificam a "Nova Classe Média" como pertencente ao segmento de baixa renda (BARKI; PARENTE, 2010; QUEZADO; COSTA; FUENTES, 2014). Nogami e Pacagnam (2011), por exemplo, mostram que, dos quarenta artigos analisados por eles, vinte e dois consideram (explicitamente ou não) a classe $\mathrm{C}$ como participante da baixa renda. Com base no exposto, optou-se por considerar as classes C, D e E como pertencentes ao segmento de baixa renda, utilizando-se o critério de classificação do IBGE, para uma renda familiar mensal, conforme descrito a seguir:

- Classe $\mathrm{A}=$ mais de 20 salários mínimos - acima de $\mathrm{R} \$ 17.600,01$;

- Classe B = entre 10 e 20 salários mínimos - entre R\$8.800,01 a R17.600,00;

- Classe $\mathrm{C}=$ entre 4 e10 salários mínimos - entre $\mathrm{R} \$ 3.720,01$ a $\mathrm{R} \$ 8.800,00$;

- Classe $\mathrm{D}=$ entre 2 e 4 salários mínimos - entre $\mathrm{R} \$ 1.760,01$ a $\mathrm{R} \$ 3.720,00$;

- Classe $\mathrm{E}=$ até 2 salários mínimos - abaixo de $\mathrm{R} \$ 1.760,01$. 
Informações mais explicadas sobre a classificação de consumidores de baixa renda, os critérios de estratificação socioeconômica, seus conceitos e segmentações encontram-se disponíveis no Apêndice A.

Para este trabalho, foram realizadas 23 entrevistas em profundidade, porém, dois dos entrevistados tinham renda familiar mensal acima de 10 salários mínimos e, por esse motivo, foram excluídos da análise. Embora não houvesse um número de entrevistas predefinidas para serem realizadas, chegou-se ao total de 21 quando se percebeu que os relatos dos entrevistados estavam apresentando repetições, concluindo-se que a saturação dos dados estava alcançada. A tabela com os dados sobre o perfil dos entrevistados encontra-se a seguir: 
Tabela 1: Perfil dos entrevistados

\begin{tabular}{|c|c|c|c|c|c|c|c|}
\hline$\#$ Nome & Idade & $\begin{array}{c}\text { Tem plano } \\
\text { atualmente? }\end{array}$ & Ocupação & Nível de ensino & Estado civil & Bairro residência & Renda mensal familiar \\
\hline 1 Renan & 22 & SIM & $\begin{array}{l}\text { auxiliar de serviços gerais, } \\
\text { ajudante de pedreiro }\end{array}$ & Ensino médio incompleto & Solteiro & Mesquita & a) Entre $R \$ 0,00$ e $R \$ 1.760,00$ \\
\hline 2 Marcos Paulo & 19 & SIM & $\begin{array}{l}\text { Repógrafo e manutenção de } \\
\text { computadores }\end{array}$ & Ensino médio incompleto & Solteiro & Taquara & a) Entre $R \$ 0,00$ e $R \$ 1.760,00$ \\
\hline 3 Aldo & 68 & SIM & Aposentado & Ensino Superior Completo & Casado(a); & Laranjeiras & c) Entre $\mathrm{R} \$ 3.720,01$ e $\mathrm{R} \$ 8.800,00$ \\
\hline 4 Raquel & 40 & SIM & Oficial de Limpeza & Ensino médio completo & Solteiro & Guadalupe & a) Entre $\mathrm{R} \$ 0,00$ e $\mathrm{R} \$ 1.760,00$ \\
\hline 5 Pedro & 51 & SIM & Advogado, tribunal de justiça & Ensino Superior Completo & Solteiro & Botafogo & c) Entre $\mathrm{R} \$ 3.720,01$ e $\mathrm{R} \$ 8.800,00$ \\
\hline 6 Patricia & 45 & SIM & Desempregada & Ensino Superior Completo & Casado(a); & Vista Alegre & b) Entre $\mathrm{R} \$ 1.760,01$ e $\mathrm{R} \$ 3.720,00$ \\
\hline 7 Maria de Lurdes & 89 & SIM & Aposentado & Ensino fundamental incompleto & Viúvo(a) & Humaitá & c) Entre $\mathrm{R} \$ 3.720,01$ e $\mathrm{R} \$ 8.800,00$ \\
\hline 8 Lourdes & 54 & SIM & Auxiliar de serviços gerais & Ensino fundamental incompleto & Solteiro & Todos os Santos & b) Entre $R \$ 1.760,01$ e $R \$ 3.720,00$ \\
\hline 9 Cleonice & 45 & SIM & Auxiliar de serviços gerais & Ensino médio incompleto & Casado(a); & Guapimirim & a) Entre $\mathrm{R} \$ 0,00$ e $\mathrm{R} \$ 1.760,00$ \\
\hline 10 Leandro & 18 & SIM & Assistente Administrativo & Ensino superior incompleto & Solteiro & Botafogo & b) Entre $R \$ 1.760,01$ e $R \$ 3.720,00$ \\
\hline 11 Jorlei & 79 & SIM & Aposentado & Ensino médio completo & Casado(a); & Leblon & b) Entre $\mathrm{R} \$ 1.760,01$ e $\mathrm{R} \$ 3.720,00$ \\
\hline 12 Jessica & 25 & SIM & Desempregada & Ensino médio completo & Solteiro & Santa Cruz & a) Entre $\mathrm{R} \$ 0,00$ e $\mathrm{R} \$ 1.760,00$ \\
\hline 13 Jaqueline & 36 & NÃO & Desempregada & Ensino médio completo & Casado(a); & Rocinha & b) Entre $R \$ 1.760,01$ e $R \$ 3.720,00$ \\
\hline 14 Glauciane & 31 & NÃO & Desempregada & Ensino médio completo & Casado(a); & Tijuca & a) Entre $\mathrm{R} \$ 0,00$ e $\mathrm{R} \$ 1.760,00$ \\
\hline 15 Fernando & 33 & SIM & Auxiliar Administrativo & Ensino médio incompleto & Casado(a); & Manguinhos & a) Entre $R \$ 0,00$ e $R \$ 1.760,00$ \\
\hline 16 Erenita & 61 & SIM & Auxiliar de serviços gerais & Ensino fundamental incompleto & Separado(a) & Bonsucesso & a) Entre $\mathrm{R} \$ 0,00$ e $\mathrm{R} \$ 1.760,00$ \\
\hline 17 Deise & 46 & SIM & Auxiliar de serviços gerais & Ensino médio incompleto & Solteiro & Nilópolis & a) Entre $\mathrm{R} \$ 0,00$ e $\mathrm{R} \$ 1.760,00$ \\
\hline 18 Denise & 55 & SIM & Aposentada & Ensino Superior Completo & Casado(a); & Leme & b) Entre $R \$ 1.760,01$ e $R \$ 3.720,00$ \\
\hline 19 Catia & 49 & SIM & Auxiliar de serviços gerais & Ensino fundamental incompleto & Separado(a) & Jacarepaguá, Cidade de Deus & a) Entre $\mathrm{R} \$ 0,00$ e $\mathrm{R} \$ 1.760,00$ \\
\hline 20 Cassiano & 40 & SIM & Auxiliar técnico de informática & Ensino fundamental completo & Casado(a); & São Cristóvão & b) Entre $R \$ 1.760,01$ e $R \$ 3.720,00$ \\
\hline 21 Alexandre & 49 & SIM & Líder & Ensino fundamental incompleto & Solteiro & Rio Comprido & b) Entre $R \$ 1.760,01$ e $R \$ 3.720,00$ \\
\hline 22 Angela & 68 & SIM & Consultora de Marketing & Ensino Superior Completo & Solteiro & Copacabana & d) Entre $\mathrm{R} \$ 8.800,00$ e $\mathrm{R} \$ 17.600,00$ \\
\hline 23 Beatriz & 70 & SIM & Aposentada & Ensino Superior Completo & Viúvo(a) & Gávea & d) Entre $\mathrm{R} \$ 8.800,00$ e $\mathrm{R} \$ 17.600,00$ \\
\hline
\end{tabular}


Seguindo a classificação de classes do IBGE, foi possível entrevistar 10 indivíduos pertencentes à classe $\mathrm{E}$, oito pertencentes à classe $\mathrm{D}$ e três pertencentes à classe C. Do total de entrevistados, nove são homens e 12 são mulheres, com idades entre 18 e 89 anos, sendo a idade média de 45 anos.

Quase todos os entrevistados (19) possuíam um plano de saúde no momento das entrevistas. Os dois que não possuíam o serviço já o tiveram em um passado próximo, de modo que sabiam opinar sobre planos de saúde. Destes 19 que possuíam planos de saúde, 17 eram titulares do plano e dois declararam-se como dependentes de um titular.

Sobre o nível de ensino dos entrevistados, quatro tinham ensino superior completo, um com ensino superior incompleto, cinco com ensino médio completo, cinco com ensino médio incompleto, um com ensino fundamental completo e os demais cinco com ensino fundamental incompleto. Tal aspecto corrobora o estudo de Ortega (2011), que cita que não é incomum que um indivíduo da classe $\mathrm{C}$, atualmente, possua nível de instrução superior, embora a maioria somente tenha chegado ao ensino médio, com parte tendo-o completado.

Em relação à ocupação dos entrevistados, 13 se encontravam empregados, quatro estavam desempregados e quatro já eram aposentados. Quanto ao seu estado civil, nove eram casados, nove eram solteiros, dois eram divorciados e apenas um viúvo.

\section{3.}

\section{Procedimentos de Coleta de Dados}

A coleta de dados ocorreu por meio de entrevistas em profundidade com consumidores de baixa renda, que apresentavam as características de perfil desejadas para a pesquisa, entre os meses de novembro de 2016 e janeiro de 2017. Todas as entrevistas foram gravadas, com o consentimento dos entrevistados, para posterior transcrição e análise. Um total de 744 minutos de entrevistas foram gravados.

Para guiar as entrevistas, um roteiro foi elaborado (disponível no Apêndice B), com pergunta baseadas na revisão de literatura. De maneira a garantir o 
entendimento correto do roteiro de entrevistas, duas entrevistas teste foram realizadas com consumidores do público alvo da pesquisa. A partir de tais entrevistas, foi possível detectar problemas nas perguntas elaboradas e, com isso, alterá-las, tornando o instrumento de coleta de dados mais conciso e claro para os entrevistados.

As entrevistas foram realizadas em diversos locais, entre eles unidades de empresas de planos de saúde, hospitais particulares e em uma universidade particular. Sempre que o ambiente não era privativo ou barulhento, o entrevistador sugeria outro local para que a entrevista fosse realizada, para garantir a total atenção do entrevistado, sua privacidade para expor seus pensamentos e que o áudio das entrevistas fosse claro quando gravado.

O entrevistador abordava os possíveis entrevistados de forma espontânea, se apresentava e explicava que era um estudante e que estava fazendo uma pesquisa para seu curso e se poderia conceder uma entrevista para falarmos do tema em questão, deixando claro que era apenas para fins acadêmicos e os dados seriam tratados anonimamente.

O pesquisador também acessou alguns diretores de operadoras de saúde, tendo sucesso e retorno em uma operadora, em qual fez algumas das entrevistas em uma de suas unidades.

Para fins de incentivo e agradecimento aos respondentes, foi oferecida uma barra de chocolate de $\mathrm{R} \$ 7,90$ da marca Cacau Show. Esse incentivo mostrou-se bastante eficaz em garantir respondentes para a pesquisa, pois, em determinados momentos, o entrevistador era abordado por pessoas desejando ser entrevistadas, enquanto ele ainda estava realizando uma entrevista. Percebia-se que os indivíduos que desejavam ser entrevistados viam o chocolate como algo de grande valor, por ser da marca em questão, comentando entre si que não era "um chocolate qualquer, é da Cacau Show". 


\section{4.}

\section{Procedimentos de Análise dos Dados}

A partir das transcrições das entrevistas, os dados coletados foram organizados, para, em seguida, serem analisados. Para o processo de organização, utilizou-se uma planilha de Excel, na qual foram expostas as principais falas dos entrevistados relativas às perguntas feitas no roteiro de entrevistas.

A organização dos dados permitiu realizar o processo de comparação dos relatos dos entrevistados, a fim de se encontrar semelhanças e diferenças no que diziam e, assim, poder comparar os achados com a revisão de literatura. Esse processo de comparação permitiu que se chegasse às categorias de análise (CARSON et al., 2005), apresentadas no capítulo a seguir.

\section{5.}

\section{Limitações da Metodologia}

A metodologia escolhida para a pesquisa deste estudo não está livre de limitações. A quantidade insuficiente de entrevistados que seria necessária para que seja representativa da população estudada é tida como uma das principais limitações. Contudo, por ser uma pesquisa exploratória, não se busca alcançar um número grande de entrevistados, a fim de se generalizar os achados (CRESWELL, 2010; MCCRACKEN, 1988).

Outra desvantagem dessa metodologia de pesquisa é a influência do entrevistador, devido às diferenças demográficas e sociais, que podem, involuntariamente, intimidar os entrevistados, ocasionando uma distorção nas respostas. Com esse receio, o pesquisador buscou deixar os entrevistados o mais à vontade possível, a fim de fazê-los sentirem-se confortáveis em responder as perguntas. Nesse sentido, conversas informais foram feitas antes do começo das entrevistas, para "quebrar o gelo" e gerar mais confiança dos entrevistados. 


\section{4.}

\section{Descrição e Análise dos Dados}

O presente capítulo apresenta a descrição e a análise dos dados coletados na pesquisa de campo, sendo dividido em três partes. A primeira parte aborda os sentimentos e as simbologias associados pelos entrevistados em possuir um plano de saúde. Na segunda parte, é abordada a questão da valorização das empresas que oferecem planos de saúde entre seus benefícios por parte dos consumidores de baixa renda entrevistados. Na terceira parte, é traçada uma comparação entre a saúde pública e o serviço de saúde privado.

\section{1.}

\section{Sentimentos e simbologias associados à posse de um plano de saúde}

Para se entender os sentimentos presentes na posse de um plano de saúde por parte de consumidores de baixa renda, é necessário, primeiramente, entender que o consumo para esses indivíduos possui diversos significados, maiores do que somente os benefícios funcionais que um bem pode lhes proporcionar. Para os consumidores entrevistados, o consumo está repleto de simbologias, de forma que sua posse remete a distinções em relação a seus pares ao alcançarem maior status social (MCCRACKEN, 2003).

Essa visão é a que permeia os sentimentos que os consumidores de baixa renda entrevistados possuíam sobre seus planos de saúde. Possuir um plano é associado a ter "segurança" e "amparo", além de sentir que, mesmo sem necessariamente tê-lo usado, "a saúde está melhorando". Mesmo entre os entrevistados que não possuem o plano, essa visão é mantida. Ambas as consumidoras que não mais têm acesso a um plano dizem que se sentem “desassistidas" e "preocupadas quanto à saúde", pois se vierem a adoecer, somente poderão contar com a rede pública.

Possuir um plano de saúde era uma realidade distante para muitos entrevistados, especialmente por não ser um serviço comum em seu círculo social, sendo mais associado a "uma coisa de rico". Possuir algo que somente "os ricos" tinham acesso, portanto, é motivo de orgulho para os entrevistados, o que pode ser explicado pois consumidores de baixa renda tendem a aspirar ao estilo de vida de 
indivíduos das classes sociais mais elevadas, por esses serem vistos como consumidores mais desenvolvidos, já que possuem acesso a mais informações e melhores produtos e serviços (CHAUVEL, 2000; HEMAIS; CASOTTI, 2014). Leandro (18 anos, assistente administrativo) fala sobre seu orgulho em possuir um plano de saúde da seguinte forma: "Tenho a cabeça erguida por eu ter condições de pagar meu próprio plano".

A partir da posse do plano de saúde, é relatada a sensação de inclusão social, conforme exposto a seguir:

Sei lá, incluso. Uma coisa que nunca tive acesso. Só ouvia alguém falando. Era uma realidade distante da minha. Quando foi me oferecido na época, eu aceitei de cara, logo. Você fica mais calmo, pois se não conseguir ir no [hospital] público, tem o plano. Me sinto satisfeito em saber que tenho essa opção (Fernando, 33 anos, auxiliar administrativo).

Diversos outros estudos sobre o comportamento de consumidores de baixa renda no Brasil discutem a questão da inclusão social por meio da posse (BARKI; PARENTE, 2010; CASTILHOS, 2007; CRUZ, 2008; MATTOSO; ROCHA, 2008). Em geral, tais estudos mostram que, mais do que o tipo de profissão exercida por esses indivíduos, é a posse de determinados bens e serviços que lhes dá maior sentimento de fazer parte da sociedade, conforme relata Marcos (19 anos, repógrafo): "me senti melhor, como a minha saúde estivesse melhorando...".

Alguns entrevistados relataram que a posse do plano de saúde representa uma garantia de possuir acesso a uma instantânea melhora de saúde e, portanto, na qualidade de vida. Relato similar foi achado nas pesquisas de Barros e Rocha (2007) e Castilhos (2007), que sugerem que o consumo possa ser uma forma de inclusão social e reflexo de uma melhora na qualidade de vida.

Os entrevistados relatam que essa qualidade de vida é algo que dificilmente alcançariam no sistema público de saúde, devido à sua precariedade, que leva a demora e perpetuação do problema de saúde. Nesses casos, vale a pena, até, fazer sacrifícios para conseguir ter acesso ao plano, conforme ilustram os relatos a seguir: 
O meu filho passou mal ano passado no dia que terminou o Carnaval, na quarta-feira de cinzas. Ele entrou no hospital um dia, operou no outro dia e saiu logo depois, entrou na quarta e saiu na sexta. Já a minha vizinha, entrou na terça, está esperando até hoje para ser operada e não consegue ser operada no Souza Aguiar. O plano de saúde é importante, mas é caro (...) mas vale a pena (Raquel, 40 anos, oficial de limpeza).

Ah, eu deixaria [de viajar para ter um plano de saúde]. Até usar menos a internet também. É uma economia que lá na frente agente ia ver uma vantagem... viajar é bacana, conhece outros lugares, mas com saúde é melhor ainda (Glauciane, 31anos, desempregada).

Uma das entrevistadas que não possui mais um plano de saúde acusa o desemprego como o principal motivo para estar nessa situação. Ela lamenta bastante o fato e diz temer por seu futuro. Ao ser questionada sobre o sentimento quando deixou de ter acesso a um plano de saúde, Jaqueline (36 anos, desempregada) responde: "Muito mal, por que quando [eu] precisava e não pude mais ter um plano de saúde, eu me vi obrigada a ir para a rede pública, e lá eu não era bem assistida".

Mattoso e Rocha (2008) indicam um sentimento similar entre seus entrevistados quando discutem o fato de terem seu "nome sujo" e, por isso, estarem impossibilitados de conseguir crédito. Para as autoras, os sentimentos negativos agudos em relação a essa situação refletem, inclusive, na identidade do consumidor, que muda por não mais poder consumir aquilo que, outrora, estava ao seu dispor. Isso é explicado por Arnould e Thompson (2005), quando indicam que o consumo ajuda a formar um senso de identidade no consumidor, fazendo com que chegue mais perto da identidade almejada e a um grupo do qual deseja pertencer.

Todavia, vale ressaltar que, por mais importante que o plano de saúde pareça ser para os entrevistados, não é visto como uma prioridade em seus gastos, já que alguns relatos mostram uma preferência por outros bens e serviços de consumo considerados supérfluos, tais como comer fora, um celular mais caro, um carro ou uma viagem. Nesse caso, parece que a perda do plano de saúde não chega a ser tão drástica quanto a perda do acesso ao crédito discutida por Mattoso e Rocha (2008), conforme ilustra o relato a seguir: 
A vida está difícil para agente, nesse momento, pra fazer qualquer tipo de redução pra poder começar a pagar um plano de saúde novamente... Meu esposo tem carro, moramos em uma casa modesta, mas eu não sei se deixaria de ter algumas coisas para poder pagar o plano de saúde. Como pobre, eu vivo decentemente (Jaqueline, 36 anos, desempregada).

Abrir mão de alguns bens e serviços de consumo, tais como um carro ou uma viagem, pode ser entendido como uma redução no padrão de vida desses consumidores, algo difícil de se fazer, especialmente por já considerarem suas vidas cheias de restrições. Após a expansão econômica e a recuperação do crescimento no Brasil, a partir da década de 2000, impulsionado pelas mudanças institucionais da década de 1990 e pela estabilização monetária e ampliação do crédito, consumidores de baixa renda passaram para outro patamar de consumo (SOUZA; KACHUBA, 2015). Voltar aos níveis anteriores, portanto, é difícil por representar uma falha, um retrocesso, o que faz alguns entrevistados remeterem à ideia de que "pobre tem seu lugar", e que esse não é em clínicas e hospitais particulares, cujo acesso é dado pelos planos de saúde.

Além disso, as reduções dos níveis de consumo para esses consumidores de baixa renda representam retornar a patamares inferiores na escala hierárquica da sociedade, sem sequer poder se diferenciar de seus pares desse segmento. Em uma sociedade que impõe a riqueza como o principal demarcador de status social, sendo produtos e serviços a forma de tangibilizar tal riqueza (MATTOSO; ROCHA, 2008), é natural entender que a despesa com a manutenção de um plano de saúde fique em segundo plano quando comparado a outros bens mais tangíveis, como um carro ou uma viagem, por exemplo.

A posse de um plano de saúde tem tamanha importância para alguns consumidores que chega a ser comentada com amigos, vizinhos e familiares que, por sua vez, aplaudem o entrevistado por seu consumo. De certa forma, possuir um plano de saúde mostra-se, para esses indivíduos de baixa renda, uma forma de diferenciação. Yaccoub (2011) explica que o consumo pode servir como uma porta de saída de uma condição de pobre para a de menos pobre, fazendo com que o indivíduo saia da "invisibilidade" e se torne destacado por possuir algo que poucos outros de seu entorno possuem. Os relatos a seguir ilustram essa situação ao destacar o sentimento de prestigio dos entrevistados por possuir o plano de saúde perante a comunidade com que convivem: 
Minha família sabe (que a entrevistada possui um plano de saúde), minha rua toda também sabe. Falo que o plano de saúde é muito bom. (Raquel, 40 anos, oficial de limpeza).

Sabem (que o entrevistado possui um plano de saúde), eu falei. Quando cheguei em casa, eu avisei, porque na minha família ninguém tem essas coisas (Marcos, 19 anos, repógrafo).

Eu comento. Contei pra eles, falei pro meu filho. Às vezes, quando eles estão passando mal e vão pra a UPA, eu falo: "Eu tenho plano de saúde e não preciso passar por isso", e eles sempre voltam reclamando que demoram horas... Com certeza, fui tratado melhor pela minha família... disseram que eu tomei vergonha na cara: "Pô, até que enfim, meu irmão, só assim você não precisa ficar penando que nem agente no hospital público". Eu já penei mesmo sem plano (Alexandre, 49 anos, líder de limpeza).

Minha irmã estava querendo ir na emergência. Aí, eu falei que graças a Deus eu tenho plano de saúde, por que depender disso aí, tu morre. Minha irmã até queria usar meu plano de saúde (Cleonice, 45 anos, Auxiliar de serviços gerais).

É importante ressaltar que, por maior que seja o envolvimento dos entrevistados com seus planos de saúde, entre aqueles da classe C esse sentimento se mostra em menor grau, conforme indica Maria de Lurdes (89 anos): "Não chega a ser 'Ah, porque eu tenho um plano de saúde'. É uma coisa necessária, importante, a pessoa fica despreocupada, e quando tiver um problema, sabe para onde vai". Esse achado é importante porque mostra que o segmento de baixa renda não pode ser tratado como um grupo homogêneo, já que seus sentimentos e pensamentos sobre bens de consumo diferem (SILVA et al., 2009).

\section{2.}

\section{Valorização das empresas que oferecem planos de saúde entre seus benefícios corporativos}

Os relatos mostram que o principal motivo para os entrevistados possuírem um plano de saúde é por ser um benefício concedido pelas empresas, pois dificilmente o teriam se essa condição não fosse oferecida a eles:

Não é todo mundo que tem condições de ter um plano de saúde (...). A Maioria das pessoas que tem plano de saúde ou tem condição financeira boa para poderem pagar individual ou quem tem um emprego onde a empresa oferece. (Patrícia, 45 anos, desempregada). 
[Eu] não ia conseguir pagar. Só trabalhando eu poderia ter [o plano de saúde] e tendo como benefício da empresa (Renan, 22 anos, ajudante de pedreiro).

Eu tenho porque vem descontando do meu salário... se fosse eu pagando, eu não iria ter. Se aumentasse meu salário, eu não ia ter, ia gastar e, quando precisasse, ia ficar desejando (Cleonice, 45 anos, auxiliar de serviços gerais).

Geralmente, a escolha do plano de saúde é feita pelo empregador e não pelo funcionário. Esse segundo pode, em alguns casos, optar por um pacote de plano mais completo, pagando, por isso, um adicional. Entre os possíveis benefícios que uma empresa pode oferecer a seus funcionários de baixa renda, o plano de saúde é um de seus preferidos. Tal fator corrobora a argumentação apresentada por Neri (2011), que destaca que a formalização do emprego com carteira assinada aumentou bastante nas últimas duas décadas no Brasil. Por consequência, esse movimento trouxe maior competitividade para contratar e reter bons funcionários, estimulando empresas a agregarem o benefício seguro de saúde para seus empregados, de forma a atrair e reter os melhores candidatos.

Esse benefício, inclusive, é visto como "essencial" entre os entrevistados na escolha da empresa onde vão trabalhar e grande motivador para manter o emprego atual. Essa afirmação, de certa forma, ajuda a entender o que Prahalad e Hart (2002) expõem quando argumentam que consumidores de baixa renda passam a admirar empresas que lhes permitem melhorar sua condição de vida. Embora os autores estivesse se referindo aos bens comercializados por tais empresas, esse paralelo parece válido quando o bem é oferecido como uma parte dos benefícios concedidos por empresas a seus funcionários. Os relatos a seguir corroboram essa questão, pois os entrevistados alegam que, mesmo se recebessem uma oferta de emprego por outra empresa, não mudariam se não lhes fosse oferecido um plano de saúde:

Não aceitaria (trabalhar em uma empresa que não oferecesse plano de saúde a seus funcionários). Era a primeira coisa que ia perguntar... Tem empresa que agente se machuca lá dentro e é com você mesmo... eu já trabalhei passando mal e não fui liberado para ir ao médico. Aqui não, agente tem o plano de saúde, tem um médico aqui embaixo e podemos ser consultados, é um pouco diferente (Renan, 22 anos, ajudante de pedreiro). 
Por isso que me mantenho no trabalho, pra poder manter meu plano de saúde. É um estímulo para eu poder me manter no trabalho. Conservando meu trabalho, eu sei que conservo meu plano de saúde (Alexandre, 49 anos, Líder de Limpeza).

[Eu] Não trocaria o benefício do plano de saúde. Pela questão de comodidade, do atendimento, de menos preocupação se eu vou conseguir pelo público um exame ou não. No particular, tenho certeza que vou conseguir. Por tudo isso, então, eu ficaria com o plano (Jaqueline, 36 anos, desempregada).

A importância dada à oferta do plano de saúde como um benefício em uma empresa é tamanha que quando aventada a possibilidade de substituição do plano de saúde por um aumento no salário em igual montante ao custo do plano, a maioria dos entrevistados relata preferir manter o serviço. Somente alguns desses consumidores demonstraram serem favoráveis ao aumento do salário em detrimento do benefício. Na visão desses indivíduos, a falta de um plano privado pode ser compensada, mesmo que de maneira inferior, pelo serviço público. Por o plano de saúde ser usado somente esporadicamente, o dinheiro investido nele poderia ser usado na compra de outros bens e serviços ou mesmo guardados para, quando necessário, despendê-lo com problemas de saúde, conforme discutem a seguir:

Eu apoio, porque não é sempre que a gente precisa (do plano de saúde), não é todo mês. A gente usa quando precisa, não é sempre, mensalmente. Pode ser um dia e só usar de novo três meses depois. $\mathrm{O}$ dinheiro estando com a gente... podemos gastar nesse dia (Marcos, 19 anos, repógrafo).

Eu ia ter que pensar, porque dependendo do que sou descontada e do que eu pago para a empresa, eu ia sofrer lá no SUS, na clínica da família (...). Acho que eu só deveria ser descontada do plano quando eu usasse, deveria ser assim, mas não é (Deise, 46 anos, auxiliar de serviços gerais).

A posse de um plano de saúde oferecido por uma empresa parece refletir, na visão dos entrevistados, que o seu emprego e a organização onde trabalham são melhores por conceder esse benefício aos seus funcionários. Indivíduos de baixa renda que trabalham em empresas que não oferecem planos de saúde, então, estariam em uma posição social inferior, não somente por não possuir acesso ao serviço, mas também porque precisam trabalhar em um local que oferece poucos benefícios e, portanto, pouco desejado por esses consumidores, conforme relata Raquel (40 anos, oficial de limpeza), quando descreve a forma como foi tratada quando seus amigos souberam que ela possui um plano de saúde: "(Meus amigos) 
ficaram bobos, porque nem toda firma oferece plano de saúde. A minha firma ofereceu".

Ao abordar a substituição do plano de saúde oferecido pela empresa por outro benefício de igual valor, todos os entrevistados foram contrários a essa opção, conforme discutem a seguir, atestando o valor que os empregados atribuem ao plano de saúde como benefício das empresas:

Não aceitaria [trocar o plano de saúde por outro benefício] por que dinheiro na mão é vendaval. Nada é mais importante que a saúde (Leandro, 18 anos, assistente administrativo).

O plano de saúde é mais importante. Outros benefícios, como academia, é luxo. Um plano não é luxo, é necessidade. Na família, o plano de saúde é muito importante, bem mais que bens materiais (Cassiano, 40 anos, auxiliar técnico de informática).

É importante ter um plano [de saúde] (...) acho que a saúde é mais importante que outro benefício (Marcos, 19 anos, repógrafo).

O plano de saúde, portanto, é um diferencial importante para empresas, especialmente quando o público contratado por elas é o de baixa renda. Os significados positivos associados a planos de saúde acabam sendo transferidos à empresa que oferece tal benefício, como se fosse um local melhor para se trabalhar. Oferecer esses serviços a seus funcionários é visto como um comprometimento dos empregadores com seus empregados, de forma que os segundos deveriam, também, se comprometer com a organização e ajudá-la a alcançar seus objetivos.

\section{3.}

\section{Comparação entre os serviços de saúde pública e saúde privada}

É importante relatar que ao longo das entrevistas, os consumidores entrevistados sempre que falam sobre seus planos de saúde, remetiam aos hospitais, clínicas e médicos associados ao plano como se fossem parte de um mesmo serviço, sem diferenciar a operadora do plano das demais organizações que fazem parte dessa rede. É claro que, sem tal rede, não há planos de saúde. Mas, o ponto levantado aqui é que em momento algum os entrevistados falavam do plano dissociado dessa rede, o que pode ser explicado por esses consumidores 
não terem tido problemas com suas operadoras, diferentemente de os entrevistados de Hemais e Casotti (2015). Assim, os entrevistados da presente pesquisa acabavam por confundir o serviço prestado pelos hospitais, clínicas e médicos privados como sendo os da operadora do plano. Quando falam do plano de saúde e o comparavam com o serviço de saúde público, faziam-no considerando os pontos positivos dos hospitais, clínicas e médicos, e não propriamente os das operadoras.

O principal incentivo para os consumidores de baixa renda entrevistados recorrerem à saúde privada é a carência que a saúde pública vem atravessando, especialmente no Rio de Janeiro. Inclusive, tal estado de precariedade do serviço público é relatado como um dos grandes incentivos para a aquisição de um plano de saúde, "especialmente quando tem reportagens" em meios jornalísticos retratando essa situação, ajudando os entrevistados a terem posições favoráveis quanto ao desejo de possuir o plano.

Para os entrevistados, o bom atendimento recebido em hospitais e clínicas privados é um dos fatores que mais pesa a favor dos planos de saúde, quando comparados ao atendimento em serviços de saúde públicos:

[O médico do plano privado trata o paciente] com dignidade. O médico conversa contigo, bota um aparelhinho, passa um exame para confirmar...) faz uma grande diferença no atendimento (Deise, 46 anos, auxiliar de serviços gerais).

Você vai... no Copa D'Or da vida e o tratamento (atendimento) é diferenciado. Te oferece um cafezinho, os médicos são todos conhecidos renomados, especialistas, cirurgiões, não sei o quê (...) no plano de saúde, você se sente mais acolhida, mais importante (Glauciane, 31 anos, desempregada).

Você é atendido mais rápido (em hospitais privados), com gente que tem mais educação. $\mathrm{O}$ atendimento é melhor, não tem malcriação com você (Lourdes, 54 anos, auxiliar de serviços gerais).

Fui muito bem tratado [no particular]. Dá bom dia, dá boa tarde. Não tenho do que reclamar (Renan, 22 anos, ajudante de pedreiro).

Por outro lado, quando falam do atendimento recebido em hospitais e clínicas públicas, os entrevistados frequentemente relatam más experiências, inclusive queixando-se de certo descaso e prepotência dos funcionários e médicos que lhes atendem: 
Tem algumas pessoas ali no (Hospital) Miguel Couto que não tratam a gente bem. Não sei se é por causa do uniforme, não sei. Falei pra moça: "Olha, eu tenho plano de saúde, mas só estou vindo aqui porque estou com a pressão muito alta... o atendimento de vocês é péssimo". Eu tenho plano de saúde e sou muito bem tratada (Raquel, 40 anos, oficial de limpeza).

Você já está cheio de dor e nos postos de saúde pegam umas mulheres que não sabem ler, nem escrever, nem nada, que chega lá toda valente, pensa que é doutora. Você está ali precisando e elas cheias de marra. Não estão nem aí para a sua dor (Lourdes, 54 anos, auxiliar de serviços gerais).

Você vai no SUS, e muito mal olham na sua cara. O médico do SUS te trata com maior descaso: "você deve estar com isso aqui. Toma esse remédio e vai procurar outro médico" (Deise, 46 anos, auxiliar de serviços gerais).

Devido a suas inúmeras restrições financeiras, é comum que consumidores de baixa renda apresentem baixa autoestima, o que acaba por lhes trazer sentimentos de exclusão social (LIVRAMENTO; HOR-MEYLL; PESSÔA, 2013). Quando sentem, portanto, que alguém os está rebaixando ainda mais, reforçando sua marginalização, passam a ter sentimentos de "revolta", conforme relatado por uma entrevistada, especialmente por acreditarem que, em clínicas e hospitais públicos, esse tipo de descaso não deveria ser direcionado a eles, pois, afinal, são "lugares para pobres".

A demora no atendimento do serviço de saúde público foi outro ponto bastante lembrado pelos entrevistados, que lhes leva a elevar a importância de possuir um plano de saúde, conforme ilustram os relatos a seguir:

O hospital público tem aquela burocracia de esperar três a quatro horas para ser atendido, quando é (Alexandre, 49 anos, líder de limpeza).

O SUS está muito ruim. Tem que esperar meses, às vezes. Dependendo da doença, a pessoa até morre, marca para meses depois (Erenita, 61 anos, auxiliar de serviços gerais).

No serviço público, tem aquela fila enorme, o exame vai marcar para daqui a seis meses pelo menos (Lourdes, 54 anos, auxiliar de serviços gerais).

Mas há também pontos favoráveis ao serviço público, tais como a qualidade dos médicos, conforme descreve Patrícia (45 anos, desempregada): "Nos hospitais públicos, principalmente nas emergências, é onde estão os melhores médicos, porque ali eles pegam cada coisa que no particular não pega”. 
Outro fator favorável ao serviço público de saúde foi o acesso gratuito a remédios, algo percebido como importante para os consumidores de baixa renda entrevistados, por representar um gasto a menos em sua despesa familiar, conforme descrito nos relatos a seguir:

O serviço público te oferece aquela farmácia que pode pegar o medicamento de graça. Já no plano de saúde, não tem isso. Tive que pagar o medicamento que eles não forneceram. Além de você ter um plano de saúde, você tem que ter dinheiro para o remédio. E se você não tiver dinheiro? (Glauciane, 31 anos, desempregada).

Saúde pública é bom, mas depende muito dos lugares. Tem lugar que é bem atendido, tem remédio que dá ali na hora. Mesmo sem condição de comprar, você vai no público, levou a receita, tem [o remédio]. Já ajuda muito. (...). A partir do momento que o privado passa um remédio e você tem condição de comprar, está ótimo. Mas, quando não tem, você sai até triste, espera até trinta dias para comprar um remédio. No público, ganha na hora (Cleonice, 45 anos, auxiliar de serviços gerais).

Em geral, consumidores de baixa renda levam em consideração a distância e o custo do deslocamento até o local onde precisam ir para adquirir produtos e serviço, quando precisam comprá-los (PARENTE; BARKI; KATO, 2005). Tal fator também foi verificado na presente pesquisa, pois o custo do transporte foi um fator decisivo, na visão dos entrevistados, para escolher entre ir a um hospital ou uma clínica de saúde pública ou privada, conforme relatado por Erenita (61 anos, auxiliar de serviços gerais):

Às vezes, eu vou na Clínica da Família (um serviço de saúde pública). Mas, agora, mesmo com o plano de saúde eu vou na clínica da família, porque é perto de onde moro e não pago passagem. Mas, se fosse longe e tivesse que pagar passagem, eu ia preferir ir pelo plano.

Há também, na rede pública, hospitais que são referências em diversas especialidades, além de outros serviços que geralmente o plano de saúde não cobre, conforme relatado a seguir:

Tem hospitais muito bons, conceituados, mas está faltando lugar, espaço. As pessoas estão sendo transferidas de lugar, essas coisas (Marcos Paulo, 19 anos, repógrafo).

Sim! [sobre utilizar um serviço público de saúde], como serviços de vacina, emergências em casos de acidentes, etc. (Denise, 55 anos, aposentada). 
Já usei para me consultar com um especialista da rede pública que me foi recomendado e era referência no que eu estava precisando (Aldo, 68 anos, aposentado).

Mesmo havendo esses pontos em favor, de uma forma geral os problemas associados pelos entrevistados ao serviço de saúde público os levam a julgaremno como "ruim", "um caos", que leva pessoas a "morrer na fila". Assim, possuir um plano de saúde no Rio de Janeiro é "quase uma necessidade”, para que possam “fugir” dessa situação precária e garantir, consequentemente, sua saúde.

O ponto mais importante para esses consumidores de baixa renda em valorizarem planos de saúde quando comparados ao serviço de saúde pública é a ideia de que, com o primeiro, são tratados com dignidade, como se fossem verdadeiros consumidores. Em um contexto de tantas privações, com sentimentos de discriminação contra eles (WALSH, 2009), poder fugir das agruras que o serviço público lhes oferece e, ainda, ser bem tratado, parece ser uma dádiva em suas vidas.

\section{5. \\ Conclusões}

O presente trabalho teve como objetivo entender os significados atribuídos por consumidores de baixa renda a planos de saúde. Para isso, foram conduzidas 21 entrevistas em profundidade com consumidores que tinham ou tiveram plano de saúde. As entrevistas foram realizadas no município do Rio de Janeiro e os entrevistados que não obedeciam aos critérios previamente estabelecidos foram excluídos da análise. A partir da análise das entrevistas, é possível chegar a algumas conclusões.

Verificou-se que, para os entrevistados, o significado de posse do plano de saúde promove, por si só, uma sensação de melhora da saúde e da qualidade de vida. Foram relatados sentimentos de segurança e amparo por possuírem acesso a tal serviço. Possuir um plano de saúde distingue o beneficiário dentre seus pares que, na maioria das vezes, não têm acesso a esse benefício. Essa diferenciação se dá via um cunho social, pois aquele que possui um plano de saúde acaba sendo associado a alguém com mais status.

A posse do plano de saúde para consumidores de baixa renda transmite confiança, pois a estrutura que possuem para cuidar de sua saúde é bastante 
satisfatória. A comparação com a rede pública de saúde, dessa forma, é inevitável, dada a falta de qualidade e zelo no atendimento. Essa satisfação com o plano de saúde é, na verdade, reflexo dos sentimentos positivos com o prestador de serviço (um hospital, por exemplo) da operadora de saúde, que pode ou não ser do mesmo grupo.

Essa carência no serviço de saúde da rede pública faz com que o consumidor atribua à posse de um plano de saúde um sentimento de melhoria no seu bem estar global, atestando o argumento de Prahalad e Hart (2002), de que o maior acesso a bens e serviços para consumidores de baixa renda faz com que estes indivíduos tenham uma melhor qualidade de vida e, assim, valorizem a empresa que lhes oferece o plano.

Há um nítido sentimento de aumento do bem-estar quando os indivíduos de baixa renda passam a ter um plano de saúde. Para alguns, a posse do plano é percebida como uma melhora no status social, para outros, isso não ocorre, pois, a posse do plano de saúde não é um bem que, na maioria dos casos, é adquirido por eles, mas sim um benefício concedido pela empresa enquanto ele trabalha lá.

Este sentimento de posse é similar ao achado por McCracken (2003), que argumenta que a transferência de significados do bem para o indivíduo permite uma melhor compreensão das influências dos processos de consumo como dos seus significados culturais. Foi observado nesta pesquisa que o sentimento referente à posse do plano de saúde para a baixa renda, para parte dos entrevistados, não é um bem que eles reivindicam integralmente, pois seus atributos simbólicos não aspiram um legítimo sucesso, por não ser propriedade do indivíduo, mas sim da empresa em que trabalha.

A literatura do consumo de baixa renda argumenta que um tipo de consumo ganha significado de status social quando este se diferencia de seus pares (CASTILHOS, 2007; BARROS; ROCHA, 2008; CRUZ, 2008). O significado da posse de um plano de saúde para consumidores de baixa renda é tido como um item valioso, porém não mais que um carro, uma viagem, um celular, por exemplo. Essa camada da população dificilmente não consumiria um plano de saúde pagando por ele de forma particular, em detrimento de outros gastos. 
Como relatado por Castilhos (2007), o consumo mostra-se pouco eficaz em remover barreiras entre classes de baixa e de alta renda. Porém, é um mecanismo de distinguir e diferenciar intra-classes sociais. Essa diferenciação faz com que os indivíduos de baixa renda almejem possuir os que outros de sua comunidade não possuem, como um celular mais moderno, roupas de marca, viagem, carro, entre outros itens para então poder se diferenciar dos demais membros.

No estudo, foi percebido que a posse do plano de saúde pelos entrevistados de baixa renda é um item de diferenciação em relação aos indivíduos em seu entorno. Porém, não há um sentimento de egoísmo, entre esses consumidores, atrelado à posse do plano de saúde, pois desejam que todos pudessem ter um plano de saúde e, consequentemente, gozar de uma melhor qualidade de vida, argumento esse pouco visto quando falam de outros bens, como carro, um celular melhor, uma reforma da casa ou outras posses. Por trás desse pensamento está a angústia de pensar em depender do serviço público de saúde e todas as suas falhas, algo que ninguém deseja a seus próximos.

\section{1.}

\section{Implicações gerenciais}

A presente pesquisa trouxe algumas conclusões que podem ser importantes para o meio empresarial. Foi possível verificar que os entrevistados entendem que a decisão de escolha do plano de saúde é feita pela empresa, mas os serviços são avaliados pelos empregados. As empresas que têm em seus quadros trabalhadores de baixa renda podem se aproveitar da presente pesquisa para mais bem entender as necessidades de seus colaboradores, suas preferências e motivações para direcionar suas estratégias de recrutamento e retenção de funcionários, já que foi verificado que o acesso a um plano de saúde é um dos principais benefícios concedidos pelas empresas na avaliação desse público.

O benefício plano de saúde é visto como um diferencial pelo empregador e também mostra aos empregados que a empresa se preocupa com a sua saúde. Dessa forma, o plano de saúde atribui valor ao cargo, no momento de recrutar esses indivíduos. Empresas que oferecem tais benefícios devem realizar ações de comunicação que falem sobre os diferenciais que possuem ao oferecerem planos de saúde, contribuindo, assim, ao aumento e zelo da qualidade de vida de seus funcionários. 
Ressalta-se, também, a importância de se ter opções de outros modelos de contratação de planos de saúde, como o modelo de franquia anual, que está tramitando para análises dos responsáveis, concomitante com consulta à

população. É um assunto em pauta no mercado de saúde, atualmente.

Independentemente desse modelo, é crucial que operadoras de planos de saúde discutam novas formas de custeio do serviço, já que o envelhecimento da população, atrelado ao aumento do custo de saúde, somado à decadência do serviço público, faz com que cresça a importância para o consumidor em ter um plano de saúde.

Um dos achados da pesquisa mostra que, como os funcionários pagam uma co-participação do seu plano de saúde oferecido por empresas, quando não há uma utilização do plano por um período longo, há um sentimento de que o serviço se torna uma despesa desnecessária. É interessante, portanto, que operadoras de planos de saúde criem ações para lembrar os significados em possuir tal benefício.

\section{2.}

\section{Sugestões e recomendações para novas pesquisas}

Embora essa pesquisa tenha encontrado indicações sobre a importância do plano de saúde para os consumidores de baixa renda, não foi possível esgotar o tema. Assim, surgem possibilidades de estudos posteriores em aprofundar mais essa linha de pesquisa.

Considerando que pesquisas acadêmicas sobre o consumo de indivíduos de baixa renda ainda são escassas, principalmente quando atrelado ao significado de consumo de planos de saúde, sugere-se que mais estudos referentes ao tema desta pesquisa sejam realizados, tendo, também, a ótica do CCT para as políticas públicas de saúde com foco nos consumidores de baixa renda como um tema ainda pouco explorado em trabalhos acadêmicos no Brasil.

Adicionalmente, sugere-se que, futuramente, este presente estudo seja refeito, para verificar como e o que mudou no comportamento dos consumidores de baixa renda em relação à importância e o significado de consumo de planos de saúde. Pode ser que a condição econômica que o país estiver atravessando possa mudar suas percepções. 
Este estudo foi baseado em entrevistas em profundidade, o que significa que o contato do pesquisador com os entrevistados foi ad hoc. Seria interessante que outros estudos consigam acompanhar um mesmo grupo de consumidores de baixa renda ao longo do tempo, para analisar mais profundamente a relação desses com o plano de saúde, e o impacto das empresas na escolha desse benefício. 


\section{6. Referências Bibliográficas}

ABREU, L. G. DE; HOR-MEYLL, L. F.; NOGUEIRA, E. M. C. Consumo de Famílias de Baixa Renda no Rio de Janeiro : um Estudo de Segmentação Baseada no Orçamento Familiar. Revista ADM.MADE, p. 19-39, 2015.

ARNOULD, E. J.; THOMPSON, C. J. Reflections Twenty Years of Research. Journal of Consumer Research, v. 31, n. 4, p. 868-882, 2005.

ARNOULD, E.; THOMPSON, C. Consumer culture theory (and we really mean theoretics): Dilemmas and opportunities posed by an academic branding strategy.

Research in Consumer Behavior, v. 11, n. July 2015, p. 3-22, 2007.

BAHIA, L. Relatório do Projeto: Dinâmica e Tendências do Mercado de Saúde Suplementar no Contexto da Regulação: Reestruturação Empresarial e Profissionalização da Gestão Ligia Bahia. [s.l: s.n.].

BARBOZA, M. Q. Milhares de brasileiros perdem o plano de saúde. Istoé, maio 2016.

BARKI, E.; PARENTE, J. Consumer Behaviour of the Base of the Pyramid Market in Brazil. October, v. 56, n. 56, p. 11-23, 2010.

BARROS, C. A "Invisibilidade" do Mercado de Baixa Renda nas Pesquisas de Marketing: as Camadas Populares Consomem ou Sobrevivem. Mercado Global, 2006.

BARROS, C.; MATTOSO, C. O Simbolismo no Consumo das Camadas Populares. Estudos ESPM, 2007.

BARROS, C.; ROCHA, E. Lógica de Consumo em um Grupo das Camadas Populares: Uma Visão Antropológica de Significados Culturais. XXXI Encontro da Anpad, p. 1-16, 2007.

BELK, R. W. Possessions and the Extended Self. Journal of Consumer Research, v. 15, n. 2, p. 139, 1988.

BICHUETTI, J. L. Profissionalização na Gestão da Saúde Suplementar: Governança Corporativa no Setor de Saúde Class Saúde, 2009.

CANTAliCE, O. et al. Valor Econômico: Análise Setorial - Hospitais Privados. São Paulo: [s.n.].

CARAZZAI, E. H. R\$ 35 para escapar do SUSGazeta do Povo, , 2008. Disponível em: <http://www.gazetadopovo.com.br/economia/r-35-para-escapardo-sus-b8dsghrbtskylz69iit2mstou>

CARNEIRO, L. A. et al. Nota de Acompanhamento de Beneficiários Análise Especial. Rio de Janeiro: [s.n.].

CARSON, D. et al. Qualitative Marketing Research. London: Sage Publications, 2005. 
CASTILHOS, R. B. Subindo o Morro: Consumo, Posição Social e Distinção Entre Famílias de Classes Populares. p. 1-16, 2007.

CHAUVEL E DE MATTOS. Chauvel e de Mattos - Consumidores de Baixa Renda. Cadernos EBAPE, v. 6, 2008.

CHAUVEL, M. A. Consumidores Insatisfeitos, uma oportunidade para as empresas MAUAD, 2000.

CHIKWECHE, T.; FLETCHER, R. Undertaking research at the bottom of the pyramid using qualitative methods. Qualitative Market Research: An International Journal, v. 15, n. 3, p. 242-267, 2012.

CHIOSINI, A. C. et al. A experiência do público de baixa renda na compra e consumo de passagens aéreas. REVISTA JOVENS PESQUISADORES, v. 7, n. 12, 2014.

CRESWELL, J. W. Projeto de Pesquisa Métodos Qualitativo, Quantitativo e Misto. 3o edição ed. Porto Alegre: Artmed editora, 2010.

CRUZ, B. DE P. A. Classe C e o Fenômeno Social TV no Brasil. Revista Administração em Diálogo, p. 23, 2014.

CRUZ, R. C. O Consumo a Partir da Lógica do Consumidor: Usando o Arcabouço das Representações Sociais. XXXII Encontro da ANPAD, p. 16, 2008.

CUNHA, J. Na crise, empresas rebaixam plano de saúde de funcionário. Disponível em: <http://www1.folha.uol.com.br/mercado/2015/10/1698205-nacrise-empresas-rebaixam-plano-de-saude-de-funcionario.shtml $>$.

DOUGLAS, M.; ISHERWOOD, B. O mundo dos Bens: Para uma antropologia do consumo. UFRJ, 2009.

ELIAS, J. Quem paga a conta pela crise econômica, Carta Capital, 2016. Disponível em: <http://www.cartacapital.com.br/revista/894/quem-paga-a-contapela-crise-economica $>$

FERRAZ, M. B. et al. Health care costs in the last four years of life for private health plan beneficiaries in Brazil. Revista panamericana de salud publica = Pan American journal of public health, v. 24, n. 2, p. 120-126, 2008.

GAIÃO, B. F. D. S.; SOUZA, I. L. DE; LEÃO, A. L. M. D. S. Consumer Culture Theory (CCT) já é uma escola de pensamento em marketing? Revista de Administração de Empresas, v. 52, n. 3, p. 330-344, 2012.

GERHARD, F. et al. Consumo na baixa renda: influência dos valores de compra hedônico e utilitário no endividamento. p. 797-824, 2015.

GIOVINAZZO, R. Um estudo sobre o desempenho e a estratégia de empresas que atuam no mercado de bens populares no Brasil. USP, 2003. 
GROSSI, P.; MOTTA, P. C. M. DA; HOR-MEYLL, L. F. O Risco Percebido na Compra de Alimentos por Consumidores de Baixa Renda. III EMA - Encontro de Marketing da ANPAD, n. c, p. 1-16, 2008.

GUIMAR ÃES, D. S. et al. Attributes and circumstances that induce inappropriate health services demand: a study of the health sector in Brazil. BMC Health Services Research, v. 15, n. 1, p. 65, 2015.

HEMAIS, M. W.; CASOTTI, L. M. Insatisfações projetadas de consumidores de baixa renda. Revista Pensamento Contemporâneo em Administração, v. 8, n. 4, p. 65-84, 2014.

HEMAIS, M. W.; CASOTTI, L. M. Reclamação de Consumidores de Baixa Renda a uma Agência de Defesa do Consumidor. sumidores de Baixa Renda a uma Agência de Defesa do Consumidor. XXXIX Encontro da ANPAD, v. p. 115., p. 1-15, 2015.

IBGE - INSTITUTO BRASILEIRO DE GEOGRAFIA E ESTATÍSTICA. Pesquisa de Orçamentos Familiares 2008-2009. Rio de Janeiro: [s.n.].

IESS - INSTITUTO DE ESTUDOS DE SAÚDE SUPLEMENTAR. Contratação de planos de saúde cresce três vezes mais rápido no Nordeste do que na média nacional, 2013.

IESS - INSTITUTO DE ESTUDOS DE SAÚDE SUPLEMENTAR. Índice De Variação De Custos Médico-hospitalares. 2016. Disponível em: <https://media.wix.com/ugd/d1d2f4_78e7f25fde7f443498a9eb7aab059193.pdf>.

JUNIOR, Á. E. Profissionalização da gestão na área de saúde tornou-se uma necessidade. Folha de São Paulo, 2014.

KAMAKURA, W. A.; MAZZON, J. A. Socioeconomic status and consumption in an emerging economy. International Journal of Research in Marketing, v. 30, n. 1, p. $4-18,2013$.

KAMAKURA, WAGNER; MAZZON, J. Critérios de estratificação e comparação de classificadores socioeconômicos no brasil. Revista de Administração de Empresas |, v. 56, n. 1, p. 55-70, 2016.

KOZINETS, R. V. Utopian enterprise : Articulating the meanings of Star Trek's culture of consumption. Journal of Consumer Research, v. 28, n. 1, p. 67-88, 2001 .

LIVRAMENTO, M. N.; HOR-MEYLL, L. F.; PESSÔA, L. A. G. D. P. Valores que motivam mulheres de baixa renda a comprar produtos de beleza. RAM Revista de Administração Mackenzie, v. 14, n. 1, p. 44-74, 2013.

LIVRAMENTO, M. N.; HOR-MEYLL, L. F.; PESSÔA, L. A. G. DE P. Mulheres de Baixa Renda: Por que Compram Produtos de Beleza? XXXV Encontro da ANPAD, p. 1-17, 2011.

MATTOSO, C. L. D. Q. Classes Sociais, Peculiaridades na Base da Pirâmide e a Possibilidade de Esquemas Classificatórios. XXXIV Encontro da Anpad, n. 1, p. 1-11, 2010. 
MATTOSO, C. L. DE Q.; ROCHA, A. DA. Building, Losing, and Reconstructing Social Identities: An Investigation Into the Symbolic Use of Credit by Poor Consumers in Brazil. Latin America Business Review, v. 9, p. 227-256, 2008.

MATTOSO, C. Q.; ROCHA, A. DA. Significados Associados às Estratégias para Solução de Problemas Financeiros dos Consumidores Pobres. XXIX EnANPAD Encontro da ANPAD, n. 2003, p. 1-15, 2005.

MCCRACKEN, G. Cultura e Consumo: Novas Abordagens ao Caráter Simbólico dos Bens e das Atividades de Consumo. Rio de Janeiro: Mauad Editora Ltda, 2003.

MCCRACKEN, G. The long interview (qualitative research methods series, volume 13). Newburry Park: Sage Publications, 1988.

MEIRELLES, R. Faces da Classe Média, Data Popular, 2014. Disponível em: $<$ http://www.secovi.com.br/files/Arquivos/faces-da-classe-media-secovimidia.pdf $>$

MOREL, A. P. S. et al. Simbolismo e extensão do self no consumo de produtos de beleza. Pretexto, 2016.

NERI, M. A Nova Classe Média: O lado brilhante da base da pirâmide. Saraiva, 2011.

NIERO, J. Mais de 40\% das pessoas que possuem seguro saúde são da classe C, Revista Apólice, 2013.

NOGAMI, V. K. D. C.; VIEIRA, F. G. D.; MEDEIROS, J. Reflexões acadêmicas e de mercado para o Marketing na base da pirâmide. Revista de Negócios, v. 17, n. 4 , p. $55-73,2012$.

NOGAMI, V. K. DA C.; PACAGNAN, M. N. Consumo da Base da Pirâmide: Uma Análise Bibliométrica do Estado da Arte na Produção Acadêmica no Brasil. XXXV Encontro da ANPAD, p. 1-17, 2011.

OLIVEIRA, A. C. F. DE; SILVA, M. G. B. DA; FILHO, E. P. DA S. Influência da marca, no segmento de costméticos, com comportamento do consumidor de baixa renda de Maceió. 2016.

PARENTE, J. G.; BARKI, E. E. R.; KATO, H. T. Consumidor de Baixa Renda: Desvendando as motivações no varejo de alimentos. XXIX EnANPAD Encontro da ANPAD, p. 16, 2005.

PARENTE, J. G.; BARKI, E.; KATO, H. T. Estratégias de Marketing para o Varejo na Baixa Renda. Encontro da ANPAD - EnANPAD, 31, p. 1-14, 2007.

PEREIRA, R. M. B. Fundos de investimento miram setor de saúde. Disponível em: <http://gehosp.com.br/2016/09/12/fundos-de-investimento-miram-setor-desaude/\#sthash.aJxgKY94.dpuf>. Acesso em: 13 set. 2016. 
PINTO, M. D. R.; FREITAS, R. C. DE; JOAQUIM, A. D. M. Consumer Culture Theory ( Cct ) No Contexto Das Experiências De Consumo De Serviços : p. 4968, 2015.

PIOVESAN, A.; TEMPORINI, E. R. Pesquisa exploratória: procedimento metodológico para o estudo de fatores humanos no campo da saúde pública. Revista de Saúde Pública, v. 29, n. 4, p. 318-325, 1995.

PONCHIO, M. C.; ARANHA, F. Necessidades, Vontades e Desejos: a Influência do Materialismo sobre a Dívida de Consumo dos Paulistanos de Baixa Renda. XXXI Encontro da Anpad, n. 2003, p. 1-16, 2007.

PRAHALAD, C. K.; HAMMOND, A. Serving the World's Poor, Profitably. Harvard Business Review, p. 10, 2002.

PRAHALAD, C. K.; HART, S. L. The Fortune at the Bottom of the Pyramid. Strategy+Business Magazine, n. 26, p. 273, 2002.

QUEZADO, I.; COSTA, R. B. L. DA; FUENTES, V. L. P. Aglomeração e Valor de Compra em Centros de Consumo de Baixa Renda. Rev. Adm. UFSM, v. 7, n. 1, p. 49-64, 2014.

RABÊLO, A. et al. Os Antecedentes do Consumo de Produtos Culturais por Consumidores de Baixa Renda. Revista Brasileira de Marketing, v. 13, n. 1, p. 75-92, 2014.

ROCHA, A. DA; SILVA, J. F. DA. Consumo na Base da Pirâmide - Estudos Brasileiros. Editora, Mauad, 2009.

ROCHA, A. DA; SILVA, J. F. DA. Inclusão Social e Marketing na Base da Pirâmide: Uma Agenda de Pesquisa. RAE Electrônica, v. 7, n. 2, p. 1-24, 2008.

ROCHA, E. Culpa e prazer: imagens do consumo na cultura de massa. Comunicação, mídia e consumo, v. 2, p. 123-138, 2005.

ROCHA, E. Invisibilidade e revelação: camadas populares, cultura e práticas de consumo. In: Consumo na Base da Pirâmida - Estudos Brasileiros. [s.l: s.n.]. p. 255 .

SILVA, A. M. DE C. E; PEREIRA, E. A. Marcas, Marketing e Consumo nos Trens Urbanos. XXXV Encontro da ANPAD, p. 1-17, 2011.

SILVA, H. M. R. DA; PARENTE, J. G.; KATO, H. T. Segmentação da Baixa Renda Baseado no Orçamento Familiar. Faces (FACE/FUMEC), v. 8, p. 98-114, 2009.

SILVA, M. DA S. A. S. Saúde Suplementar no Brasil : um balanço a partir da literatura técnico-científica nacional no período 2001-2013. PUC, 2014.

SOUZA, D. S. DE; AYROSA, E. A. T.; CERCHIARO, I. B. "Do Bom e Do Melhor": O Consumo de Bens de Luxo na Classe C. Sociedade, Contabilidade e Gestão, p. 80-97, 2013. 
SOUZA, M. A. PIERUCCINI; KACHUBA, D. Novas interpretações para o consumo de massa no Brasil : uma análise sob a ótica dos planos econômicos. $\mathrm{n}$. 2015, p. 329-352, 2015.

THAÍS LETÍCIA MIAZZO GARCIA ORTEGA; ANDRÉ LUIS FASSA GARCIA. Os hábitos de consumo da nova classe $\mathrm{C}$ brasileira nas ruas e na internet. COGNITIO, 2011.

VILLELA, F. Planos de saúde perdem 1,3 milhão de clientes em um ano. Disponível em: <http://economia.uol.com.br/noticias/redacao/2016/05/02/planosde-saude-perdem-13-milhao-de-clientes-em-um-ano.htm>.

WALSH, G. Disadvantaged consumers' experiences of marketplace discrimination in customer services. Journal of Marketing Management, v. 25, $\mathrm{n}$. 1-2, p. 143-169, 2009.

WEDEL, M.; KAMAKURA, W. Introduction to the special issue on market segmentation. International Journal of Research in Marketing, v. 19, n. 3, p. $181-183,2002$.

YACCOUB, H. "Gato" de energia elétrica: do Público ao Privado, do "jeitinho" ao crime. Journal of Chemical Information and Modeling, v. 53, n. 9, p. 16891699, 2013.

YACCOUB, H. A chamada "nova classe média": cultura material, inclusão e distinção social. Horizontes Antropológicos, v. 17, p. 197-231, 2011. 


\section{7.}

\section{Apêndices}

\section{1 .}

\section{Apêndice A - Classificação dos consumidores de baixa renda no Brasil}

A classificação dos indivíduos e/ou famílias como pertencentes a uma determinada classe social não é homogênea entre países, nem mesmo havendo consenso dentro do Brasil sobre como isso ocorre. Em alguns casos, divide-se a população em classes a partir de sua renda, enquanto em outros ocorre por meio do nível de escolaridade do chefe da família e os bens que a família possui (KAMAKURA; MAZZON, 2016).

Entretanto, grande parte das estratégias de marketing das empresas segregam seus consumidores de acordo com o trinômio segmentação, escolha de grupo-alvo e posicionamento de marketing, que agrupa consumidores que apresentam necessidades e preferências semelhantes (WEDEL; KAMAKURA, 2002). Todavia, essa classificação parece ser mais voltada para a segmentação de consumidores de mais alta renda do que seus pares de baixa renda. É difícil conceber que empresas utilizarão uma estratégia de venda personificada a consumidores de baixa renda, com esforço de venda e publicidade maior, porém com menores margens de lucro. O marketing de massa é o mais utilizado nesse caso, imaginando-se que a camada de mais baixa renda é similar, mesmo que diferentes autores indiquem o contrário (SILVA; PARENTE; KATO, 2009).

De maneira a conhecer melhor as características dos indivíduos que fazem parte de cada classe socioeconômica, um novo critério de classificação tem sido adotado pelo Governo Brasileiro. O critério escolhido, elaborado pela Associação Brasileira de Empresas e Pesquisas (ABEP), foi feito com base no trabalho de estratificação econômica de Kamakura e Mazzon (2016), a partir do qual foram desenvolvidos três classificadores. O classificador mais completo e adotado leva em conta 35 itens, tais como anos de escolaridade do responsável pela família, renda bruta familiar mensal, número de dormitórios, banheiros e acesso a água e esgoto, quantidade de bens duráveis que tem posse e número de empregados na residência. Esses itens são ajustados por variáveis como região geográfica, tipo de 
localização do domicílio, além da quantidade de adultos e menores presentes no domicílio.

A Figura 2 apresenta o tamanho dos estratos sociais segundo o novo modelo da ABEP, verificando uma diferença expressiva nos perfis socioeconômicos.

Figura 2: Estratificação econômica do Brasil.

Tamanho dos Estratos - renda das famílias

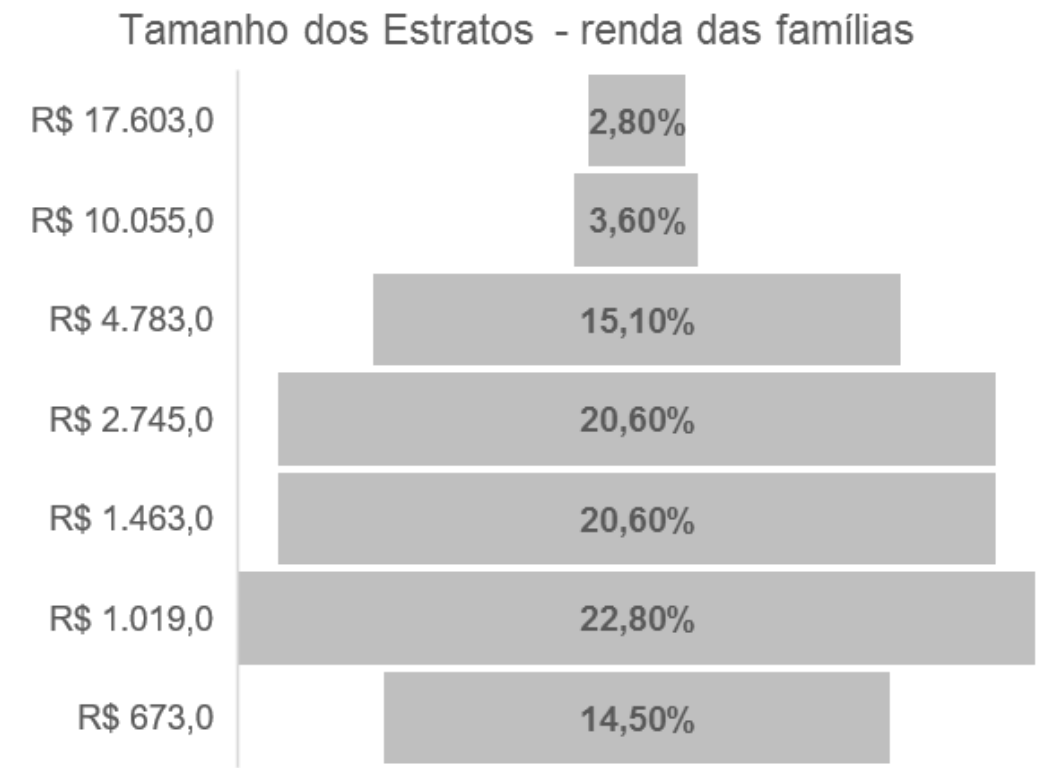

Fonte: Kamakura e Mazzon (2016).

Entre os itens da classificação, Kamakura e Mazzon (2013) constataram que a despesa com assistência à saúde no Brasil tem aumentado no total dos gastos familiares. Em 1975, 4,2\% do total das despesas familiares eram para assistência à saúde, passando para 6,5\% em 2003 e 7,2\% em 2009. Esse aumento das despesas com saúde é vista tanto no ambiente rural como no urbano, refletindo, por um lado, o enriquecimento da população, mas, por outro, a necessidade de buscar atendimento na saúde suplementar, visto a precariedade da saúde pública (IBGE INSTITUTO BRASILEIRO DE GEOGRAFIA E ESTATÍSTICA, 2010).

A participação da despesa total com a assistência à saúde foi a que mais aumentou de 2008 a 2009, em comparação com o biênio 2002-2003, tanto nos centros urbanos $(10,6 \%)$, quanto no meio rural $(20,4 \%)$, retratando um forte 
aumento dos gastos das famílias no seu dispêndio total (KAMAKURA; MAZZON, 2013).

O tema que cerca a classificação do que representa a camada de baixa renda ainda carece de mais estudos para o mercado brasileiro, diferentemente de outros países, onde há uma maior preocupação e é fonte de mais pesquisas na área (NOGAMI; PACAGNAN, 2011). Essa carência de estudos pode estar aparente por alguns motivos (i) as maiores empresas não têm foco no segmento baixa renda do Brasil; (ii) desconhecimento desse mercado inibe os investimentos; (iii) insuficiência de investimentos em Pesquisa e Desenvolvimento para essa categoria de consumidores; (iv) atingimento do lucro por volume de produção e venda sem alterar significativamente a qualidade do produto ou serviço ofertados e (v) o preconceito que ainda atinge esse público inibindo maiores oportunidades de negócios (NOGAMI; PACAGNAN, 2011).

Mas, as oportunidades de negócio para o consumidor de baixa renda devem levar em consideração que o mercado não é homogêneo, há particularidades, desejos e necessidades de consumo diferentes dentro dessa classe social. Denominações de mais pobres ou menos pobres na camada de baixa renda foi descrita por Castilhos (2007), que apresenta três graduações: a Elite dos Pobres, cujos principais membros bem-sucedidos são os comerciantes locais, os Pobres e o Pobres-Pobres, que se distinguem pela posse dos bens, principalmente alimentação e moradia, sendo os Pobres-Pobres caracterizados por estarem próximos à linha da miséria.

Neri (2011), por sua vez, apresenta uma segmentação diferente para o segmento de baixa renda, atribuindo a um grupo desse segmento a denominação de "Nova Classe Média" brasileira, também conhecida como classe C. Segundo o autor, esse grupo de consumidores deseja consumir e tem poder de compra para tal, de forma que adquirem produtos e serviços, tais como carro, computador, TV a cabo, e casa própria, em sua cesta de compras. 


\section{2.}

\section{Apêndice B - Roteiro de entrevistas com os consumidores}

Bom dia / tarde. Prazer, me chamo Luiz Felipe, sou aluno universitário da PUC do Rio de Janeiro e estou fazendo um trabalho de conclusão de curso. Para isso, estou realizando uma pesquisa com consumidores de serviços privados de saúde. Você tem ou teve plano de saúde? As perguntas que irei fazer não tem respostas certas ou erradas. O importante é o seu ponto de vista sobre o tema.

Essa pesquisa é anônima. Isso significa que você não será identificado(a), não citarei seu nome na pesquisa. A nossa conversa será apenas para meus registros. Fique à vontade, então, para falar o que quiser. As informações que você me passar serão confidenciais, usadas apenas para fins acadêmicos, não interferindo na sua relação com seu plano de saúde ou com qualquer estabelecimento.

Para facilitar o meu trabalho e poder analisar melhor as respostas, eu vou gravar a nossa conversa. Assim, posso lhe dar mais atenção. Essa gravação só será utilizada para a minha análise e nada mais, ok?

Se precisar fazer alguma pergunta, pode interromper a nossa conversa a qualquer momento, ok?! 


\begin{tabular}{|c|c|c|c|}
\hline Informação & Variável & Pergunta & Pergunta \\
\hline $\begin{array}{l}\text { Perfil do } \\
\text { entrevistado }\end{array}$ & Nome & Qual é o seu nome? & \\
\hline $\begin{array}{l}\text { Perfil do } \\
\text { entrevistado }\end{array}$ & $\begin{array}{l}\text { Data de } \\
\text { nascimento }\end{array}$ & Qual é a sua data de nascimento? & \\
\hline $\begin{array}{l}\text { Associações ao } \\
\text { plano de saúde }\end{array}$ & $\begin{array}{l}\text { Percepção do } \\
\text { consumidor }\end{array}$ & $\begin{array}{l}\text { Quando falo em plano de saúde, o que vem à sua } \\
\text { cabeça? } \\
\text { Isso é bom ou ruim? }\end{array}$ & \\
\hline $\begin{array}{l}\text { Perfil de usuário } \\
\text { de plano de } \\
\text { saúde }\end{array}$ & $\begin{array}{l}\text { Possuidores de } \\
\text { plano de saúde }\end{array}$ & $\begin{array}{l}\text { Você acha que qualquer pessoa pode ter um plano de } \\
\text { saúde, independentemente da idade ou renda? }\end{array}$ & \\
\hline $\begin{array}{l}\text { Perfil de usuário } \\
\text { de plano de } \\
\text { saúde }\end{array}$ & $\begin{array}{l}\text { Identificação com } \\
\text { o plano de saúde }\end{array}$ & $\begin{array}{l}\text { Você poderia descrever que tipo de pessoa você acha } \\
\text { que possui plano de saúde? } \\
\text { Opção de abordagem do entrevistador: } \\
\text { Você acha que as pessoas que tem plano de saúde são } \\
\text { mais ricas? Por quê? }\end{array}$ & \\
\hline $\begin{array}{l}\text { Perfil do } \\
\text { entrevistado }\end{array}$ & Plano de Saúde & Você tem plano de saúde? (Sim / Não) & \\
\hline $\begin{array}{l}\text { Direcionamento } \\
\text { das entrevistas }\end{array}$ & & ENTREVISTADO POSSUI PLANO DE SAUDE & $\begin{array}{l}\text { ENTREVISTADO NĀO POSSUI PLANO DE } \\
\text { SAUDE ATUALMENTE }\end{array}$ \\
\hline $\begin{array}{l}\text { Perfil do } \\
\text { entrevistado }\end{array}$ & Plano de Saúde & $\begin{array}{l}\text { Qual é a operadora e o plano? } \\
\text { Você é o titular ou dependente? }\end{array}$ & $\begin{array}{l}\text { Já teve plano de saúde? Qual era? } \\
\text { Você era o titular ou dependente? }\end{array}$ \\
\hline
\end{tabular}




\begin{tabular}{|c|c|c|c|}
\hline $\begin{array}{l}\text { Perfil do } \\
\text { entrevistado }\end{array}$ & $\begin{array}{l}\text { Motivo de não ter } \\
\text { plano de saúde }\end{array}$ & & Por que você não tem mais plano de saúde? \\
\hline $\begin{array}{l}\text { Perfil do } \\
\text { entrevistado }\end{array}$ & $\begin{array}{l}\text { Tempo que tem } \\
\text { plano de saúde }\end{array}$ & $\begin{array}{l}\text { Há quanto tempo você tem plano de saúde, } \\
\text { aproximadamente? Quando foi a primeira vez que você } \\
\text { teve plano de saúde? }\end{array}$ & $\begin{array}{l}\text { Há quanto tempo você não tem mais plano de saúde, } \\
\text { aproximadamente? Quando foi a primeira vez que você } \\
\text { teve plano de saúde? }\end{array}$ \\
\hline $\begin{array}{l}\text { Perfil do } \\
\text { entrevistado }\end{array}$ & $\begin{array}{l}\text { Utilização do } \\
\text { serviço de saúde } \\
\text { privado }\end{array}$ & $\begin{array}{l}\text { Você utilizou algum serviço de saúde privado (consulta, } \\
\text { exame, internação, emergência, etc.) nos últimos } 12 \\
\text { meses? }\end{array}$ & $\begin{array}{l}\text { Você utilizou algum serviço de saúde privado (consulta, } \\
\text { exame, internação, emergência, etc.) nos últimos } 12 \\
\text { meses? }\end{array}$ \\
\hline $\begin{array}{l}\text { Frequência de } \\
\text { utilização de } \\
\text { serviço de } \\
\text { saúde }\end{array}$ & $\begin{array}{l}\text { Quantidade } \\
\text { vezes que utilizou } \\
\text { o plano em } 12 \\
\text { meses }\end{array}$ & $\begin{array}{l}\text { Quantas vezes você costuma usar um serviço de saúde } \\
\text { privado por ano? } \\
\text { a) Nenhuma, nunca usei } \\
\text { b) Pelo menos } 1 \text { vez por ano } \\
\text { c) 2-3 vezes por ano } \\
\text { d) Todo mês }\end{array}$ & $\begin{array}{l}\text { Quantas vezes você costumava usar um serviço de } \\
\text { saúde privado por ano? } \\
\text { a) Nenhuma, nunca usei } \\
\text { b) Pelo menos } 1 \text { vez por ano } \\
\text { c) 2-3 vezes por ano } \\
\text { d) Todo mês }\end{array}$ \\
\hline $\begin{array}{l}\text { Perfil do } \\
\text { entrevistado }\end{array}$ & $\begin{array}{l}\text { Forma de } \\
\text { pagamento }\end{array}$ & $\begin{array}{l}\text { Se a resposta da pergunta acima for da 'b" em diante: } \\
\text { Você usa o plano de saúde, paga particular ao alguém } \\
\text { paga para você? } \\
\text { Opção de abordagem do entrevistador: } \\
\text { - Você faz algum tratamento de saúde? } \\
\text { - Você tem alguma doença crônica ou foi uma ida }\end{array}$ & $\begin{array}{l}\text { Se a resposta da pergunta acima for da 'b" em diante: } \\
\text { Você usou o plano, pagou o serviço ou alguém pagou } \\
\text { para você? } \\
\text { Opção de abordagem do entrevistador: } \\
\text { - Você faz algum tratamento de saúde? } \\
\text { - Você tem alguma doença crônica ou foi uma ida } \\
\text { esporádica? }\end{array}$ \\
\hline
\end{tabular}




\begin{tabular}{|c|c|c|c|}
\hline & & esporádica? & \\
\hline $\begin{array}{l}\text { Sentimento em } \\
\text { relação ao custo }\end{array}$ & $\begin{array}{l}\text { Utilização versus } \\
\text { o custo de plano }\end{array}$ & $\begin{array}{l}\text { Quando você não utiliza o plano da saúde por um } \\
\text { período longo, você acha que é um custo } \\
\text { desnecessário? }\end{array}$ & $\begin{array}{l}\text { Quando você não utilizava o plano da saúde por um } \\
\text { período longo, você achava que era um custo } \\
\text { desnecessário? }\end{array}$ \\
\hline $\begin{array}{l}\text { Motivos para } \\
\text { possuir o plano } \\
\text { de saúde }\end{array}$ & $\begin{array}{l}\text { Motivo de } \\
\text { escolha }\end{array}$ & Por que você tem esse plano de saúde específico? & Por que você tinha esse plano de saúde específico? \\
\hline $\begin{array}{l}\text { Importância em } \\
\text { possuir }\end{array}$ & $\begin{array}{l}\text { Atributos do } \\
\text { plano de saúde }\end{array}$ & $\begin{array}{l}\text { O que é fundamental que um plano de saúde tenha? } \\
\text { Liste as principais qualidades em um plano de saúde }\end{array}$ & $\begin{array}{l}\text { Para você, o que mais faz falta em não ter plano de } \\
\text { saúde? Porquê? } \\
\frac{\text { Nota para o entrevistador: Sugerir que o entrevistado }}{\text { cite exemplos }}\end{array}$ \\
\hline $\begin{array}{l}\text { Importância em } \\
\text { possuir }\end{array}$ & $\begin{array}{l}\text { Diagnóstico da } \\
\text { importância }\end{array}$ & $\begin{array}{l}\text { Para você, é importante possuir esse plano de saúde? } \\
\text { Por quê? }\end{array}$ & $\begin{array}{l}\text { Para você, era importante possuir esse plano de saúde? } \\
\text { Por quê? }\end{array}$ \\
\hline $\begin{array}{l}\text { Importância do } \\
\text { serviço }\end{array}$ & $\begin{array}{l}\text { Atributos do } \\
\text { plano de saúde }\end{array}$ & $\begin{array}{l}\text { Seu plano oferece o que você destacou como mais } \\
\text { importante? }\end{array}$ & $\begin{array}{l}\text { Seu plano oferecia o que você destacou como mais } \\
\text { importante? }\end{array}$ \\
\hline $\begin{array}{l}\text { Atitude com } \\
\text { relação aos } \\
\text { serviços que } \\
\text { utiliza }\end{array}$ & $\begin{array}{l}\text { Serviços } \\
\text { utilizados pelo } \\
\text { cliente }\end{array}$ & $\begin{array}{l}\text { Quais serviços ou benefícios que você usa do seu plano } \\
\text { de saúde? Poderia listar alguns? }\end{array}$ & $\begin{array}{l}\text { Quais serviços ou benefícios que você mais usava do } \\
\text { seu plano de saúde? Poderia listar alguns? }\end{array}$ \\
\hline $\begin{array}{l}\text { Sentimentos } \\
\text { com relação ao } \\
\text { atendimento no } \\
\text { serviço de }\end{array}$ & $\begin{array}{l}\text { Atitude positiva, } \\
\text { negativa ou } \\
\text { neutra }\end{array}$ & $\begin{array}{l}\text { Como você avalia o atendimento do seu plano de saúde } \\
\text { (ou falar o nome do plano de saúde do entrevistado)? } \\
\text { Alguma vez você já foi mal atendido(a) nesse plano } \\
\text { de saúde? (caso sim: com foi o episódio?) }\end{array}$ & $\begin{array}{l}\text { Como você avalia o atendimento do plano de saúde que } \\
\text { você tinha (ou falar o nome do plano de saúde do } \\
\text { entrevistado)? } \\
\quad \text { Alguma vez você já foi mal atendido(a) nesse plano }\end{array}$ \\
\hline
\end{tabular}




\begin{tabular}{|c|c|c|c|}
\hline saúde & & $\begin{array}{l}\text { Você reclamou? Para quem? Foi atendido no que } \\
\text { queria? Ficou satisfeito? } \\
\text { Para o entrevistador: perguntar se o entrevistado } \\
\text { conhece agência reguladora (ANS, por exemplo) }\end{array}$ & $\begin{array}{l}\text { de saúde? (caso sim: com foi o episódio?) } \\
\text { Você reclamou? Para quem? Foi atendido no que } \\
\text { queria? Ficou satisfeito? } \\
\text { Para o entrevistador: perguntar se o entrevistado } \\
\text { conhece agência reguladora (ANS, por exemplo) }\end{array}$ \\
\hline $\begin{array}{l}\text { Sentimento } \\
\text { sobre o plano de } \\
\text { saúde }\end{array}$ & $\begin{array}{l}\text { Sentimento de } \\
\text { posse com o } \\
\text { plano de saúde }\end{array}$ & $\begin{array}{l}\text { Como você se sentiu quando passou a ter um plano de } \\
\text { saúde? } \\
\text { Você se imagina sem um plano de saúde atualmente? } \\
\text { Porquê? }\end{array}$ & $\begin{array}{l}\text { Como você se sentiu quando não teve mais acesso ao } \\
\text { plano de saúde? } \\
\text { Nota para o entrevistador: Queremos saber: quanto (ou } \\
\quad \text { o quê) o entrevistado deixaria de consumir ou } \\
\text { aceitaria uma redução de salário para ter } \\
\text { novamente um plano de saúde? }\end{array}$ \\
\hline $\begin{array}{l}\text { Percepção } \\
\text { quanto ao } \\
\text { pertencimento à } \\
\text { uma camada da } \\
\text { população }\end{array}$ & $\begin{array}{l}\text { Conhecimento } \\
\text { dos grupos de } \\
\text { referência sobre } \\
\text { a posse do plano } \\
\text { de saúde por } \\
\text { parte do } \\
\text { entrevistado }\end{array}$ & $\begin{array}{l}\text { Seus amigos, vizinhos e família sabem que você tem } \\
\text { plano de saúde? Como eles souberam? } \\
\text { Opção do entrevistador: Você que contou? } \\
\text { Houve mudança na forma que você foi tratado por } \\
\text { saberem que você tem plano de saúde? Qual foi a } \\
\text { reação deles? }\end{array}$ & $\begin{array}{l}\text { Seus amigos, vizinhos e família souberam que você não } \\
\text { tem mais plano de saúde? Como eles souberam? } \\
\text { Opção do entrevistador: Você que contou? } \\
\text { Houve mudança na forma que você foi tratado por } \\
\text { saberem que você não tem mais plano de saúde? Qual } \\
\text { foi a reação deles? }\end{array}$ \\
\hline \multirow[t]{2}{*}{ Status Social } & $\begin{array}{l}\text { Atitude positiva, } \\
\text { negativa ou } \\
\text { neutra }\end{array}$ & $\begin{array}{l}\text { Você acha que possuir plano de saúde é sinal de status } \\
\text { social? Por quê? }\end{array}$ & $\begin{array}{l}\text { Você acha que quem possui plano da saúde tem melhol } \\
\text { status social? Por quê? }\end{array}$ \\
\hline & $\begin{array}{l}\text { Atitude positiva, } \\
\text { negativa ou }\end{array}$ & $\begin{array}{l}\text { O que você acha das pessoas que não tem plano de } \\
\text { saúde? Por quê? }\end{array}$ & \\
\hline
\end{tabular}




\begin{tabular}{|c|c|c|c|}
\hline & neutra & & \\
\hline $\begin{array}{l}\text { Motivos para } \\
\text { possuir o plano } \\
\text { de saúde }\end{array}$ & $\begin{array}{l}\text { Comparação com } \\
\text { o serviço público }\end{array}$ & $\begin{array}{l}\text { Você já utilizou ou utilizaria um serviço público de } \\
\text { saúde, mesmo tendo plano? Em quais casos você } \\
\text { escolheria um atendimento público ao privado? }\end{array}$ & $\begin{array}{l}\text { Você já utilizou ou utilizaria um serviço público de } \\
\text { saúde, mesmo tendo plano? Em quais casos você } \\
\text { escolheria um atendimento público ao privado? }\end{array}$ \\
\hline $\begin{array}{l}\text { Qualidade do } \\
\text { Serviço }\end{array}$ & $\begin{array}{l}\text { Base de } \\
\text { comparação }\end{array}$ & $\begin{array}{l}\text { E quando falo em saúde pública, o que vem à sua } \\
\text { cabeça? } \\
\text { Isso é bom ou ruim? }\end{array}$ & $\begin{array}{l}\text { E quando falo em saúde pública, o que vem à sua } \\
\text { cabeça? } \\
\quad \text { Isso é bom ou ruim? }\end{array}$ \\
\hline $\begin{array}{l}\text { Comparação } \\
\text { entre saúde } \\
\text { pública e } \\
\text { privada }\end{array}$ & $\begin{array}{l}\text { Atributos da } \\
\text { saúde pública } \\
\text { versus a saúde } \\
\text { privada }\end{array}$ & $\begin{array}{l}\text { Na sua opinião, qual é a principal diferença entre a } \\
\text { saúde pública e a saúde privada? }\end{array}$ & $\begin{array}{l}\text { Na sua opinião, qual é a principal diferença entre a } \\
\text { saúde pública e a saúde privada? }\end{array}$ \\
\hline Perfil & $\begin{array}{l}\text { Base de } \\
\text { comparação }\end{array}$ & $\begin{array}{l}\text { Além do seu plano de saúde, você já ouviu falar de } \\
\text { outros planos? Caso sim, quais? } \\
\text { Qual você prefere? } \\
\text { Por quê? } \\
\text { Qual plano de saúde você mais gostaria de ter? } \\
\text { Qual plano de saúde você menos gostaria de ter? }\end{array}$ & $\begin{array}{l}\text { Além do plano de saúde que você tinha, quais outros } \\
\text { você conhece? } \\
\text { Qual você prefere? } \\
\text { Por quê? } \\
\text { Qual plano de saúde você mais gostaria de ter? } \\
\text { Qual plano de saúde você menos gostaria de ter? }\end{array}$ \\
\hline $\begin{array}{l}\text { Percepção de } \\
\text { preço }\end{array}$ & Custo $x$ benefício & $\begin{array}{l}\text { Você acha caro, barato ou justo o preço do plano de } \\
\text { saúde? }\end{array}$ & $\begin{array}{l}\text { Você acha caro, barato ou justo o preço do plano de } \\
\text { saúde? }\end{array}$ \\
\hline $\begin{array}{l}\text { Conhecimento } \\
\text { dos preços }\end{array}$ & & $\begin{array}{l}\text { Quanto custa para a empresa o plano de saúde por } \\
\text { funcionário? Você sabe? }\end{array}$ & $\begin{array}{l}\text { Quanto custa para a empresa o plano de saúde por } \\
\text { funcionário? Você sabe? }\end{array}$ \\
\hline $\begin{array}{l}\text { Preferência } \\
\text { entre plano de }\end{array}$ & $\begin{array}{l}\text { Decisão de } \\
\text { compra / }\end{array}$ & $\begin{array}{l}\text { Se você pudesse optar em ter o plano de saúde ou } \\
\text { outro benefício do mesmo valor, você continuaria com o }\end{array}$ & $\begin{array}{l}\text { Se você pudesse optar em ter o plano de saúde ou } \\
\text { outro benefício do mesmo valor, você continuaria com o }\end{array}$ \\
\hline
\end{tabular}




\begin{tabular}{|c|c|c|c|}
\hline $\begin{array}{l}\text { saúde ou outro } \\
\text { benefício }\end{array}$ & $\begin{array}{l}\text { importância do } \\
\text { serviço }\end{array}$ & plano de saúde? & plano de saúde? \\
\hline $\begin{array}{l}\text { Preferência } \\
\text { entre plano de } \\
\text { saúde ou } \\
\text { aumento de } \\
\text { salário }\end{array}$ & $\begin{array}{l}\text { Decisão de } \\
\text { compra / } \\
\text { importância do } \\
\text { serviço }\end{array}$ & $\begin{array}{l}\text { E se a empresa cancelasse o plano de saúde para } \\
\text { poder aumentar o salário proporcionalmente, você } \\
\text { apoiaria essa atitude? }\end{array}$ & $\begin{array}{l}\text { E se a empresa cancelasse o plano de saúde para } \\
\text { poder aumentar o salário proporcionalmente, você } \\
\text { apoiaria essa atitude? }\end{array}$ \\
\hline $\begin{array}{l}\text { Atitude com } \\
\text { relação ao plano } \\
\text { de saúde }\end{array}$ & $\begin{array}{l}\text { Perda do } \\
\text { benefício }\end{array}$ & $\begin{array}{l}\text { Se uma pessoa perdesse o benefício do plano de saúde } \\
\text { que a empresa oferece, você acha que ela iria adquirir } \\
\text { um plano de saúde pagando particular? Por quê? }\end{array}$ & $\begin{array}{l}\text { Se uma pessoa perdesse o benefício do plano de saúde } \\
\text { que a empresa oferece, você acha que ela iria adquirir } \\
\text { um plano de saúde pagando particular? Por quê? }\end{array}$ \\
\hline $\begin{array}{l}\text { Perfil / Classe } \\
\text { social }\end{array}$ & Profissão & $\begin{array}{l}\text { Você trabalha? } \\
\text { Caso sim, o que você faz como trabalho/ocupação? }\end{array}$ & $\begin{array}{l}\text { Você trabalha? } \\
\text { Caso sim, o que você faz como trabalho/ocupação? }\end{array}$ \\
\hline $\begin{array}{l}\text { Perfil / Classe } \\
\text { social }\end{array}$ & Escolaridade & $\begin{array}{l}\text { Qual é o seu nível de ensino? } \\
\text { a) Ensino fundamental incompleto } \\
\text { b) Ensino fundamental completo } \\
\text { c) Ensino médio incompleto } \\
\text { d) Ensino médio completo } \\
\text { e) Ensino superior incompleto } \\
\text { f) Ensino superior completo }\end{array}$ & $\begin{array}{l}\text { Qual é o seu nível de ensino? } \\
\text { a) Ensino fundamental incompleto } \\
\text { b) Ensino fundamental completo } \\
\text { c) Ensino médio incompleto } \\
\text { d) Ensino médio completo } \\
\text { e) Ensino superior incompleto } \\
\text { f) Ensino superior completo }\end{array}$ \\
\hline Perfil & Estado Civil & $\begin{array}{l}\text { Qual é o seu estado civil? } \\
\begin{array}{l}\text { a) Solteiro(a); } \\
\text { b) Casado(a); } \\
\text { c) Separado(a)/Divorciado(a); }\end{array}\end{array}$ & $\begin{array}{l}\text { Qual é o seu estado civil? } \\
\text { a) Solteiro(a); } \\
\text { b) Casado(a); } \\
\text { c) Separado(a)/Divorciado(a); }\end{array}$ \\
\hline
\end{tabular}




\begin{tabular}{|c|c|c|c|}
\hline & & d) Viúvo(a) & d) Viúvo(a) \\
\hline $\begin{array}{l}\text { Perfil / Classe } \\
\text { social }\end{array}$ & Moradia & Em qual bairro você mora? & Em qual bairro você mora? \\
\hline Classe social & Renda & $\begin{array}{l}\text { Você diria que a renda mensal da sua família fica entre: } \\
\text { a) Entre } R \$ 0,00 \text { e } R \$ 1.760,00 \\
\text { b) Entre } R \$ 1.760,01 \text { e } R \$ 3.720,00 \\
\text { c) Entre } R \$ 3.720,01 \text { e } R \$ 8.800,00 \\
\text { d) Entre } R \$ 8.800,00 \text { e } R \$ 17.600,00 \\
\text { e) Acima de } R \$ 17.600,00\end{array}$ & $\begin{array}{l}\text { Você diria que a renda mensal da sua família fica entre: } \\
\begin{array}{l}\text { a) Entre } R \$ 0,00 \text { e } R \$ 1.760,00 \\
\text { b) Entre } R \$ 1.760,01 \text { e } R \$ 3.720,00 \\
\text { c) Entre } R \$ 3.720,01 \text { e } R \$ 8.800,00 \\
\text { d) Entre } R \$ 8.800,00 \text { e } R \$ 17.600,00 \\
\text { e) Acima de } R \$ 17.600,00\end{array}\end{array}$ \\
\hline
\end{tabular}

Aqui terminamos a entrevista. Há alguma coisa a mais que você gostaria de acrescentar que eu não tenha abordado?

Muito obrigado por ter participado dessa pesquisa. A sua contribuição foi muito importante para o desenvolvimento do meu trabalho. Obrigado. 